\title{
El Reto de las Exportaciones de China para los Países en Desarrollo
}

\section{The Challenge of Chinese Exports for Developing Countries}

Jaime Torres González*

\begin{abstract}
Resumo: La emergencia de China en el comercio internacional está produciendo grandes reacomodamientos en la economía mundial. El presente estudio analiza experiencias de sectores de producción de equipos electrónicos y estrategias competitivas de empresas líderes chinas basadas en el uso de economías de escala. La competencia china no sólo afecta a las naciones desarrolladas sino que también se da en sectores de baja y media tecnología, donde se generan millones de empleos en países en desarrollo. En la medida que en China coexisten sectores de moderna tecnología con otros atrasados, especialmente en áreas rurales, se analiza el problema de la "economía dual" y la existencia de millones de trabajadores migrantes que engrosan las plantillas de industrias que generan una fuerte competencia para los países de menor desarrollo productivo. Como China vive hoy un continuado proceso de urbanización, se concluye que persistirá un largo período en la producción de bienes de baja y media complejidad, lo que significa que las demás naciones en desarrollo deben prepararse, y efectuar profundas transformaciones sociales y económicas, para no sucumbir ante tan fuerte y duradera presión competitiva.
\end{abstract}

Palavras-chave: Competitividad global. Competencia internacional China. Economías de escala. Países en desarrollo. Economía dual.

\begin{abstract}
The emergence of China in international trade is producing large rearrangements in the global economy. The present study examines experiences of production sectors of electronic equipment and the competitive strategies of Chinese leading companies based on the use of economies of scale. Chinese competition affects not only developed nations but also occurs in low- and medium-technology, where millions of jobs are created in developing countries. To the extent that in China coexist modern technology sectors with other backward, especially in rural areas, it is analyzed the problem of "dual economy" and the existence of millions of migrant workers who fill jobs in labor intensive industries that generate strong competition for the less developed countries. As China today is experiencing a continuing process of urbanization, it is concluded that it will persist a long time in the production of goods of low and medium complexity, which means that other developing nations must prepare and should make profound social and economic changes in order not to succumb under so strong and lasting competitive pressure.
\end{abstract}

* Economista de la Universidad Nacional de Colombia. M.Sc. en Desarrollo Económico. Ph.D. en Ciencias Políticas. Investigador en el programa posdoctoral de la Universidade Federal do Rio Grande do Sul (UFRGS). Profesor del Programa de Comercio Internacional de la Universidad de Bogotá Jorge Tadeo Lozano. E-mail: jaime.torresg@utadeo.edu.co 
Keywords: Global competitiveness. China. International competition. Economies of scale. Developing countries. Dual economy.

JEL Classification: F2; F5; F6; L1; L5.

\section{Introdução}

El propósito del presente análisis es dimensionar el rápido crecimiento de las exportaciones de China en relación con el de otras naciones del planeta, y especialmente con el futuro competitivo de los países en desarrollo. Se plantea la hipótesis de que la vertiginosa conquista de mercados por las empresas que producen en China incidirá no solamente en una gran presión competitiva con las naciones industrializadas, sino también con aquellas en proceso de desarrollo, dada la necesidad china de continuar incorporando a cientos de millones de trabajadores que aún viven en zonas rurales de baja productividad. Se plantea que esta competencia será dura en las próximas décadas pues el modelo chino de combinar un gran apoyo estatal con la competencia económica interna está demostrando que cada nuevo día puede producir bienes industriales que penetran favorablemente en todos los mercados del mundo. Para demostrar esta dinámica se ha dividido el trabajo en cuatro secciones: la primera muestra -utilizando cifras de la Organización Mundial del Comericio / OMC - cómo la China ha recuperado sitios de liderazgo en la economía mundial, de los cuales gozó establemente en siglos anteriores. Se le hace un seguimiento al crecimiento reciente de sus participaciones de mercado en las industrias de componentes electrónicos, de procesamiento de datos, equipos de oficina y telecomunicaciones, en las cuales muy rápidamente - y especialmente a partir de su ingreso a la OMC en 2001 -, ha ganado participaciones importantes. En la segunda sección se plantea cómo la política industrial desplegada por el estado chino ha propiciado a través de sus planes quinquenales un decidido apoyo a su tejido empresarial para utilizar intensamente las ventajas de las economías de escala, mejorar sus adiciones de valor, escalar tecnológicamente y conquistar mayores mercados externos. En la tercera sección se analizan las implicaciones políticas del ascenso chino, tanto respecto de las naciones desarrolladas como con aquellas en desarrollo. Se le presta especial atención al problema de la "economía dual" que existe en China, que es objeto de políticas estatales de absorción productiva sin precedentes en el planeta, dada su capacidad de afectación sobre cientos de millones de migrantes internos, y se relaciona con la penetración global del comercio de textiles y confecciones, aquel que genera amplio empleo en países en desarrollo, observándose que la competencia china desplaza crecientemente producciones anteriormente atendidas por exportadores de países en desarrollo. En la última parte se concluye que las diferentes estrategias productivas chinas continuarán operando con gran fuerza hacia el futuro, implicando que sus competidores en países de menor desarrollo relativo -como los latinoamericanos-, tendrán que 
realizar grandes esfuerzos para reinventar sus tejidos sociales y productivos para competir exitosamente contra esta gran nación que nuevamente empieza a ocupar sitios de privilegio en el concierto mundial.

\section{La Masiva Inserción de China al Comercio Internacional será Duradera}

La República Popular China ha presentado vertiginosos crecimientos de sus volúmenes de producción interna y de comercialización internacional durante las décadas recientes, partiendo de niveles muy bajos hacia los años 1980s. La China pobre, invadida por poderes extranjeros y carente de tecnologías de punta es un fenómeno que duró relativamente poco en términos históricos, ya que esta nación había sido una de las más desarrolladas durante muchos siglos, desde las primeras dinastías del Imperio Chino. En palabras del autor Ye Zicheng: ${ }^{1}$

China es un caso único en la historia de la civilización mundial. Poco más de veinte grandes civilizaciones han desaparecido en la historia mundial. [...] China es el único país que ha mantenido su civilización por más de 5.000 años, incluyendo su lenguaje hablado y escrito, y sus tradiciones culturales y educativas, que son perdurables símbolos de la nación [...] Tal como ciertos autores extranjeros reconocen, China estuvo entre los más ricos y poderosos países del globo durante la mayor parte de su historia [...] Historiadores chinos señalan el año 202 A.C. como el de fundación de la Dinastía Han, que se constituyó como poder mundial antes del Imperio Romano [...] El ejército de la Dinastía Han excedía el millón de soldados (el de Roma 650.000) y el sistema de carreteras - construido y heredado de la Dinastía Qin, totalizaba $6.800 \mathrm{Km}$, mientras el Romano alcanzó los $5.984 \mathrm{Km}$. El Imperio Chino también desarrolló más sofisticados sistemas monetario, económico y de seguridad que aquellos de Roma [...] De manera diferente a la usanza Romana, donde sólo las élites de los países conquistados fue asimilada, en China los pueblos asimilados en su conjunto se identificaron como chinos, adoptaron el idioma, el vestido y los métodos agrícolas [...] China alcanzó una unidad que fue soportada por las masas, quienes creyeron firmemente en la unificación nacional. (ZICHENG, 2011, p. 30-33).

Las cifras del comercio internacional a partir del año 1948 y hasta el 2012 muestran la predominancia económica de los países occidentales, especialmente de los Estados Unidos y Europa, ${ }^{2}$ quienes concentraron más de la mitad del comercio mundial hasta los años 70 (Gráficas 1 y 2). El declive de la participación de EEUU en la exportación de bienes es notable, habiéndose reducido desde el

1 Ye Zicheng es profesor de Relaciones Internacionales de la Escuela de Estudios Internacionales de la Universidad de Pekín y es autor de numerosas publicaciones sobre China y su relación con el exterior. Traducción de los textos en inglés por el autor del presente escrito.

2 Se toman las cifras de la Organización Mundial del Comercio (OMC). Para el caso de la Unión Europea se contabiliza su Expo/Impo exclusivamente con países por fuera de sus 27 Estados miembros actuales. Es decir, el comercio entre sus 27 miembros se considera comercio interno. 
21.7\% en 1948 al 8.6\% en 2012. La participación Europea creció en los años de reconstrucción post Segunda Guerra Mundial, alcanzando su máximo a principios de los años 1970 y descendiendo a continuación, gracias a los negativos efectos de las crisis energética y monetaria de esa década. A raíz de la crisis financiera mundial del 2008, la Unión Europea de los 27 ve declinar nuevamente su participación hasta el 35\% que tenía en 1948, y es de esperar que continúe su reducción, dadas las casi nulas tasas de crecimiento que presenta en la actualidad.

Gráfica 1 - Exportación Mundial de Mercancías 1948-2012 / Partic. \%

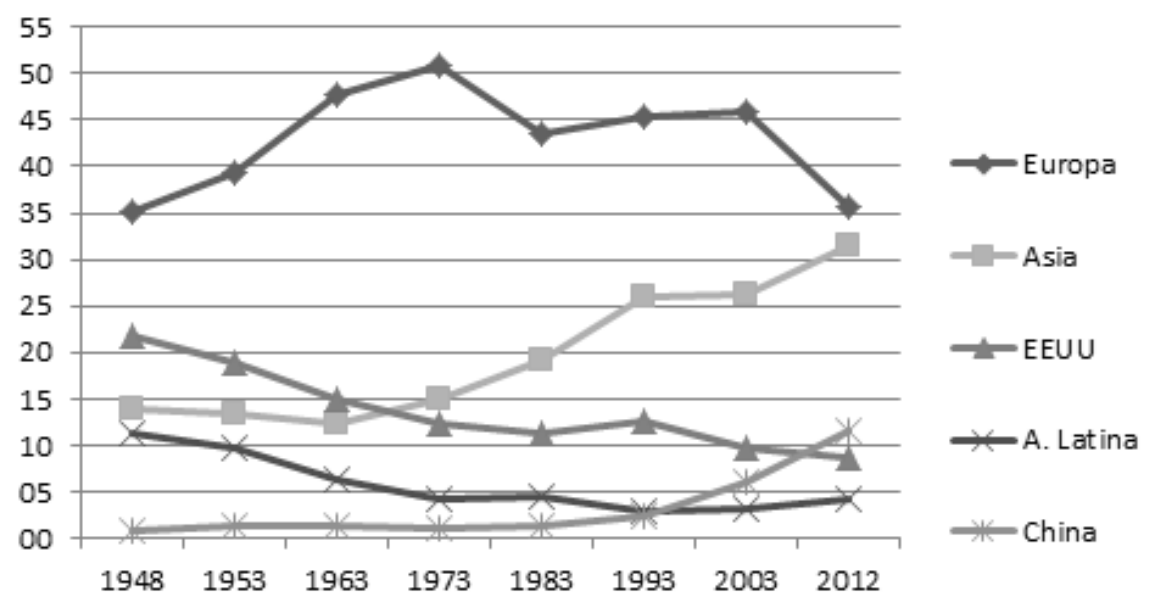

Fuente: World Trade Organization (2013).

La participación de América Latina también fue claramente decreciente en este período (de manera similar a la del África: 3.5\%), ya que se redujo a casi un tercio hacia el 2012, cuando explicó el 4.2\% del comercio mundial. Latinoamérica presentó un moderado ascenso en sus cifras comerciales a principios del siglo XXI, gracias a la mejora de los términos de intercambio de los precios de los recursos naturales que exportan las naciones Suramericanas (BANCO CENTRAL DE ARGENTINA, 2013). A estas trayectorias declinantes se opone el consistente ascenso de los países del Asia Oriental: en los años 60 y 70 estuvo explicado por el rápido crecimiento del Japón, a partir de los años 80 y 90 por los tigres asiáticos: Corea del Sur, Taiwán, Singapur y Hong Kong, mientras que en los 90 emerge con fuerza la R. P. China. La trayectoria ascendente asiática continúa a principios del siglo XXI en la medida que la industrialización de países como India, Tailandia, Indonesia, Malasia, Filipinas, y más recientemente Vietnam, se constituye en una constante del desarrollo de estas naciones. En 2012 el comercio proveniente del Asia constituyó el 31.5\% del total mundial y dadas sus altas tasas anuales de crecimiento, se 
espera que en pocos años supere la participación de la Unión Europea. De acuerdo con la Comisión Económica para América Latina:

La continuación del crecimiento de las economías de Asia es un hecho que define al siglo XXI. Se estima que esta región aportará cerca del 60\% del crecimiento del producto mundial hasta 2025. Cuatro de las mayores diez economías del mundo estarían en Asia en 2025: China, India, Indonesia y Japón. En 2030, la participación del este de Asia en el PIB mundial alcanzaría el 23\%, superando a Europa (22,5\%) y América del Norte (19,2\%). (COMISSIÓN ECONÓMICA PARA AMÉRICA LATINA Y EL CARIBE, 2014 p. 42).

Gráfica 2 - Importación Mundial de Mercancías 1948-2012 / Partic. \%

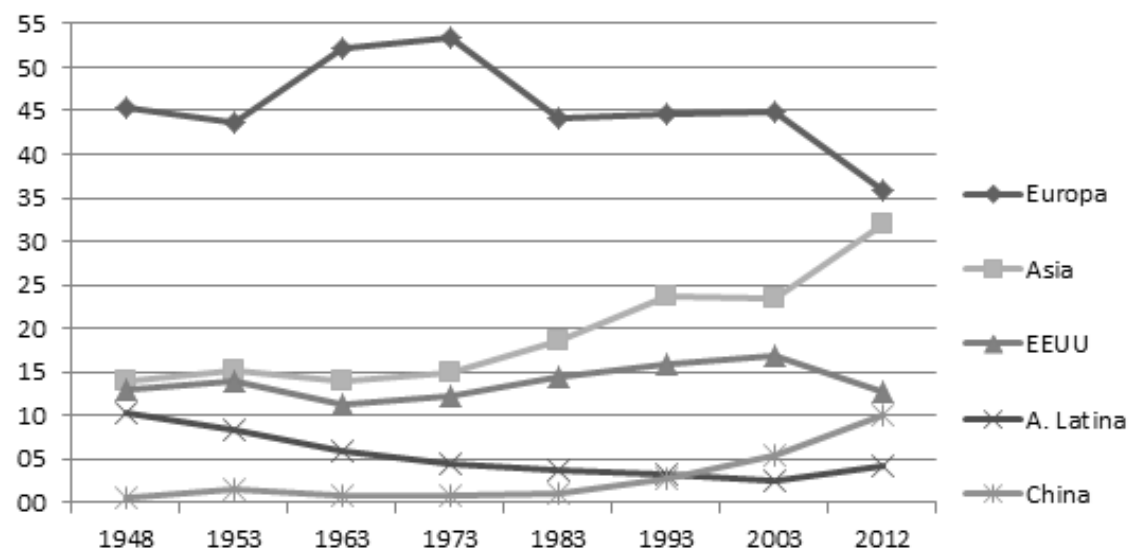

Fuente: World Trade Organization (2013).

Según la OMC, el valor de las exportaciones de productos de todos los países del mundo (medidas en Dólares de los EEUU) fue de US\$17.9 billones $^{3}$ en 2012. Dada la caída de las ventas del líder exportador mundial hasta 2009 (Alemania) debido a la crisis del 2008/9, la China se consolidó a partir del 2010 como el mayor país exportador del mundo, posición que ha venido consolidando desde entonces.

\subsection{Distribución Mundial de la Exportación de Productos en 2012}

El sector que individualmente participa con mayor valor entre los bienes transados globalmente es el de Petróleo y Combustibles (Gráfica 3), con un 19\% de las exportaciones mundiales, indicando la gran importancia que los productos fósi-

3 Un billón se expresa en este estudio con doce ceros (un millón de millones), a diferencia del sistema inglés, donde se toma por nueve ceros (ó mil millones). 
les tienen en la matriz energética actual del planeta. En este valor se incluyen tanto los productos crudos como los derivados de la petroquímica, siendo los países del Medio Oriente los de mayor participación en la venta de crudos, mientras que la exportación de derivados cuenta con gran volumen en naciones industrializadas como los EEUU, la Unión Europea, Canadá y Corea.

Entre los grandes bloques exportadores que siguen en importancia, con participación cercana al 10\% del total, se encuentran el sector Agrícola, los Productos Químicos, los de Tecnologías de la Informática y Comunicaciones (TIC's), y con un 7\% los Automotores. Los mayores exportadores agrícolas son los países desarrollados: En 2012 los EEUU participaron con el 10\% del total, la Unión Europea con el 9.7\%, Canadá 3.4\% y Australia 2.2\%. Naciones emergentes les siguieron: el Brasil se ubicó como tercer gran exportador con el 5.6\%, la China en el cuarto puesto $4.1 \%$ e Indonesia en el sexto lugar con el $2.4 \%$.

Gráfica 3 - Principales Productos Exportados - Mundo 2012

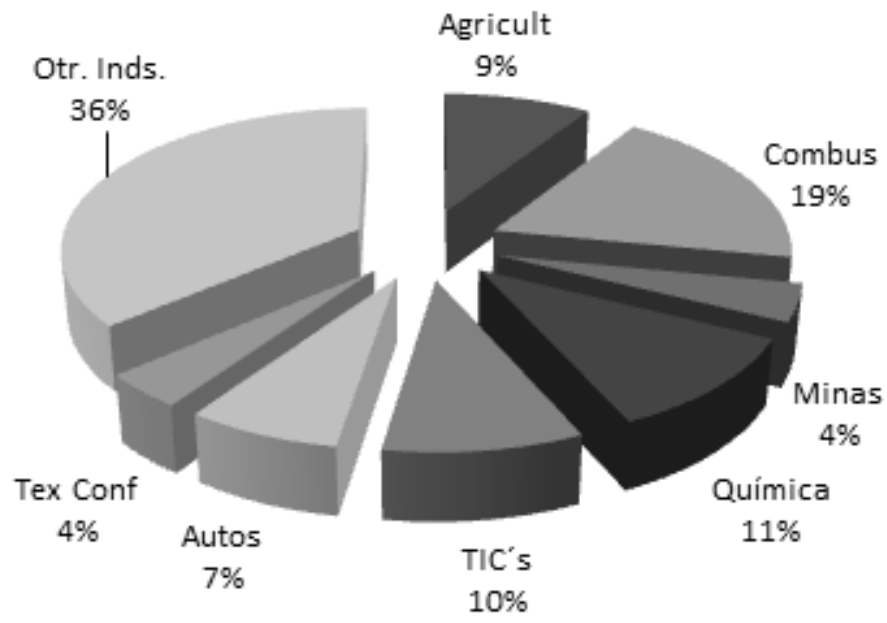

Fuente: World Trade Organization (2013).

Igualmente en las industrias química y farmacéutica la Unión Europea, EEUU y Suiza dominan los mercados internacionales. Países orientales como Japón, Corea y Taiwán son también grandes jugadores. En el caso de la China, su crecimiento como exportador de Químicos fue el más importante entre 2000 y 2012, multiplicando 2.8 veces sus exportaciones y superando a países como Suiza, Japón, Corea, Taiwán y Canadá. Otros grandes grupos exportadores se analizarán a continuación, haciendo énfasis en la creciente participación de la R. P. China en el comercio mundial de manufacturas. 


\subsection{Industrias Chinas Exportadoras de Tecnología versus Otros Países Líderes}

Si comparamos las exportaciones de Bienes Manufacturados de los principales participantes en el comercio internacional entre 1990 y 2012 (Gráfica 4), es claro que la China no sólo se ha posicionado como el mayor exportador en valores monetarios (US $\$ 1.9$ billones en 2012), superando las ventas extra-Unión Europea de los 27 (US $\$ 1.7$ billones) y a los EEUU (US\$ 1.1 billones), sino que también presenta las más altas tasas de crecimiento durante los últimos 22 años: un impresionante $45.4 \%$ anual en promedio. Un crecimiento similar no se reporta en las estadísticas mundiales para ningún otro país de importancia económica global. Y además, para que una nación con el tamaño de China logre sostener tanto tiempo un crecimiento exportador de esta magnitud, indica que importantes aspectos de su estructura social, económica y comercial están muy sólidamente fundamentados. Si bien es cierto que en años recientes y gracias a la crisis financiera del 2008, el crecimiento de las exportaciones de todas las naciones se ha reducido, China -junto con la India- continuó presentando la tasa de crecimiento exportador más elevada del globo: $15.2 \%$ anual entre 2010 y 2012.

Gráfica 4 - Exportadores de Manufacturas (US\$ Miles Mill.)

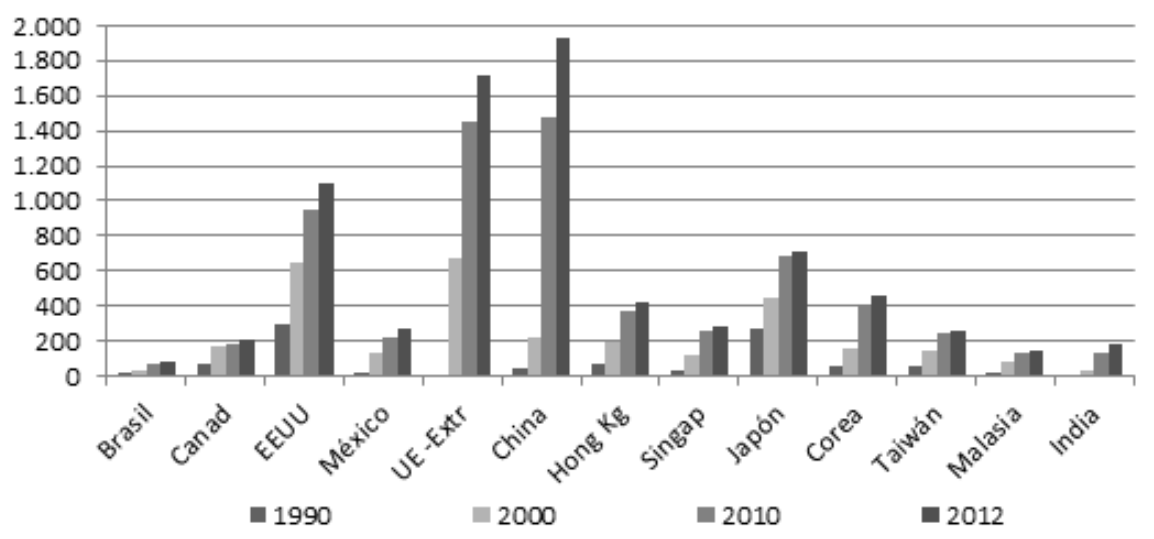

Fuente: World Trade Organization (2013).

Si se toma otros de los grandes sectores industriales de la economía mundial actual (ver Gráficas 5, 6, 7 y 8) centrándose en aquellas que están en la vanguardia tecnológica, es decir, las Industrias de Informática y Telecomunicaciones (TIC), que participan con un $9.3 \%$ del comercio global, se observa un espectacular crecimiento de la participación de China:

a) Equipos de Telecomunicaciones: En 2012 la China exportó US $\$ 229.5$ mil millones y superó en un $10 \%$ la suma de las exportaciones combinadas 
de los siguientes seis mayores exportadores de estos equipos: EEUU, UE, México, Japón, Corea del Sur y Taiwán.

b) Equipos de Oficina y Telecomunicaciones: Las exportaciones chinas por US\$ 538 mil millones en 2012 significaron el 32.3\% del total mundial. Si exceptuamos las re-exportaciones de Hong Kong, ${ }^{4}$ el siguiente mayor exportador fueron los EEUU con un $8.4 \%$ del total global, es decir, solo un poco más de la cuarta parte de las exportaciones chinas.

c) Equipos de Procesamiento de Datos y de Oficina: Para el año 2010 China ya era el indiscutido mayor productor mundial. En 2012 su facturación externa fue de US $\$ 228$ mil millones, superando con largueza a los EEUU (US\$ 51 mil millones) y a Hong Kong (US\$ 56 mil millones).

d) Componentes Electrónicos: El año 2010 China superó ligeramente al hasta entonces mayor productor mundial (Taiwán) y en 2012, con ventas externas por US\$ 82.3 mil millones, acrecentó su distancia sobre Taiwán en un $24.5 \%$, mientras que aventajó al tercer exportador (Corea) en un $76 \%$.

Gráfica 5 - Expo Equipo Telecomunicaciones (USS Mill.)

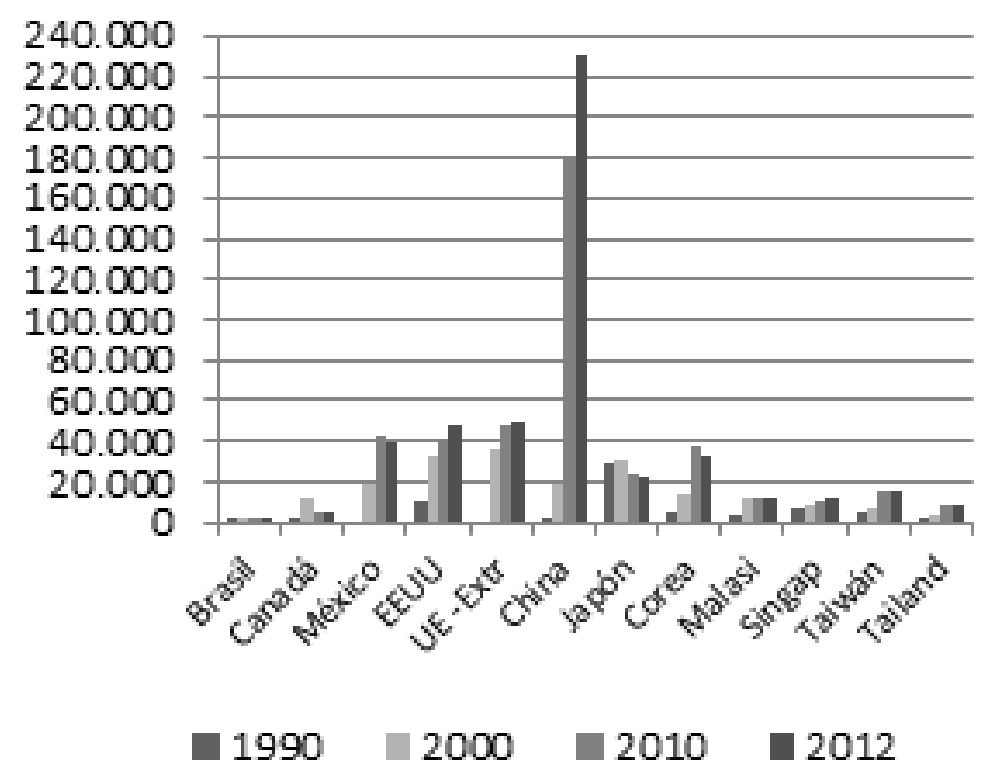

Fuente: World Trade Organization (2013).

$4 \quad$ La gran mayoría de exportaciones de Hong Kong corresponden a re-exportaciones, de las cuales una amplia proporción proviene de la China continental. 
Gráfica 6 - Expo Equipos Oficina y Telecomunicaciones (US\$ Mill.)

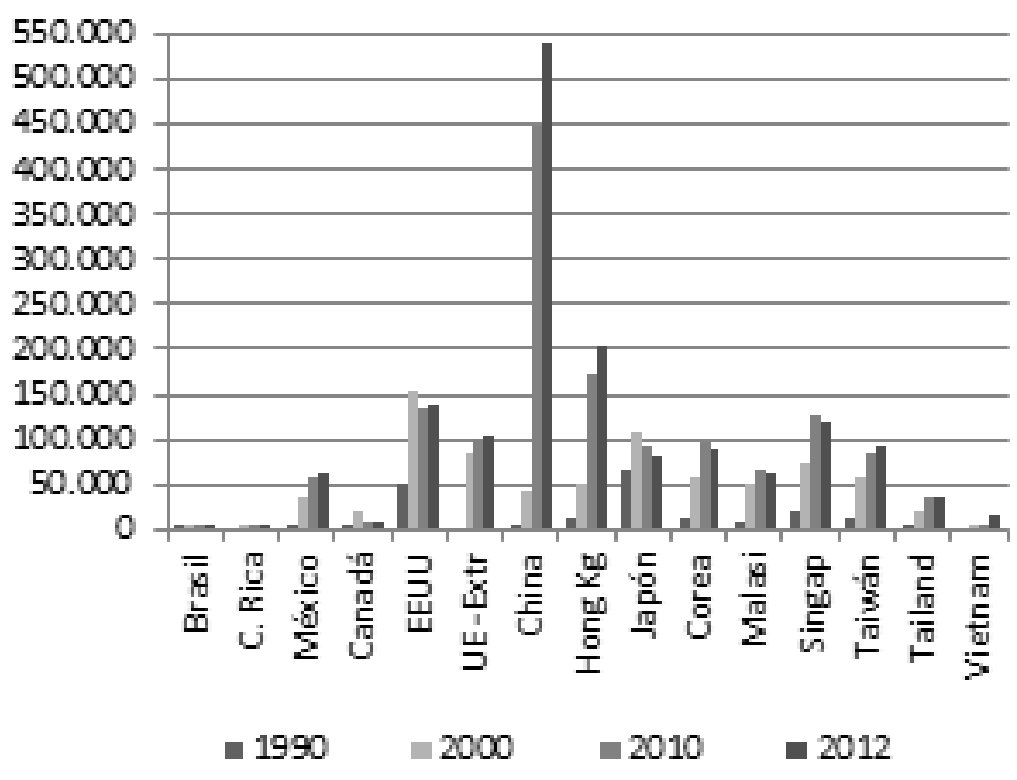

Fuente: World Trade Organization (2013).

Gráfica 7 - Expo Equipos Proceso Datos y Oficina (US\$ Mill.)

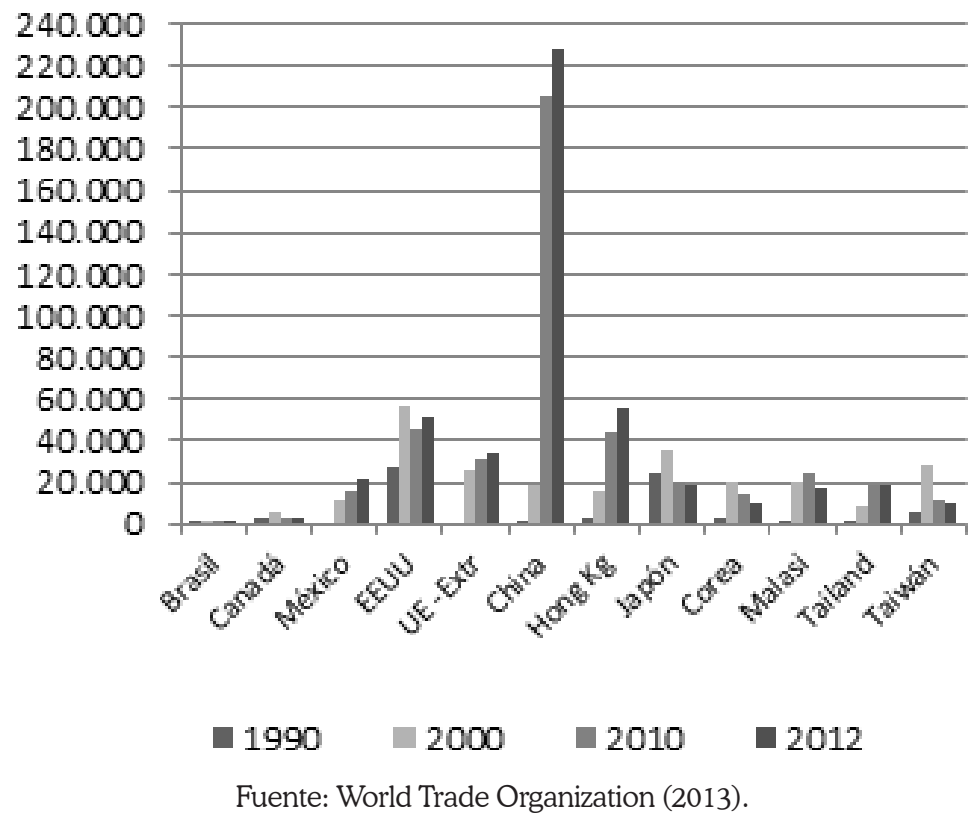

TORRES GONZÁLEZ, J. El Reto de las Exportaciones de China para los Países... 
Gráfica 8 - Exportación Componentes Electrónicos (US\$ Mill.)
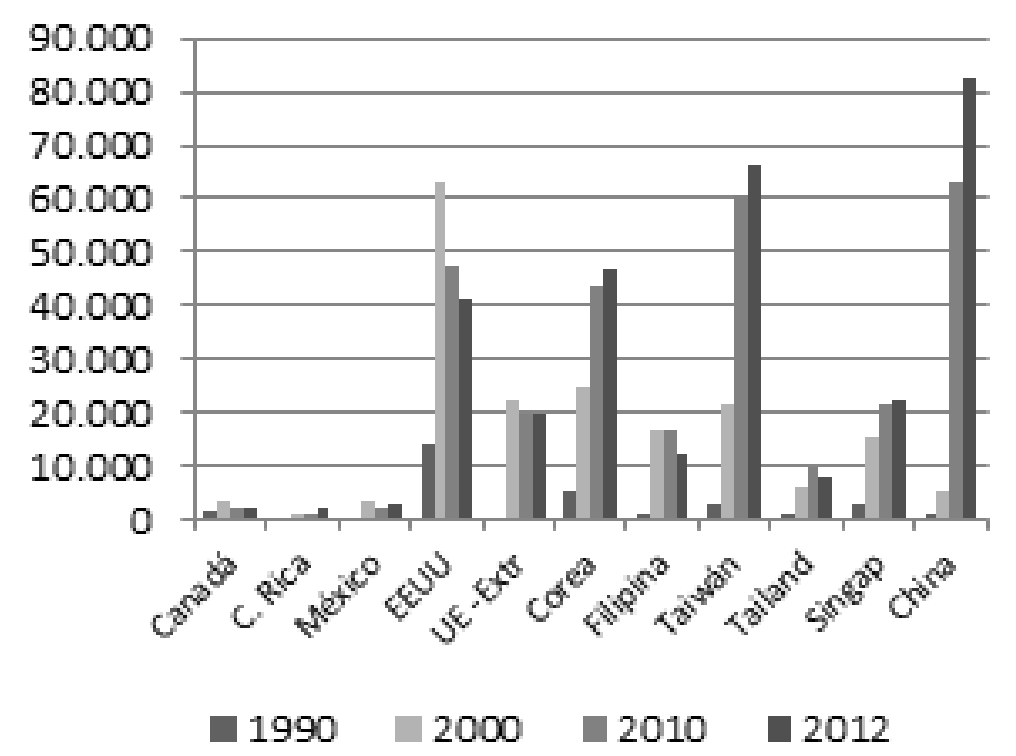

Fuente: World Trade Organization (2013).

\subsection{Redistribución Mundial de la Producción de Equipos de Oficina, Procesamiento de Datos y Telecomunicaciones 1990-2012}

Si acumulamos los valores exportados de los ocho principales países productores de Equipos de Oficina, de Procesamiento de Datos y de Telecomunicaciones (Gráficas 5, 6 y 7), encontramos que la R. P. China participaba con un modesto $2 \%$ de dichas exportaciones en 1990, monto similar a México, y muy por debajo de los líderes Japón y EEUU, quienes exportaban tres cuartas partes del total mundial. Hacia el año 2000 se hizo evidente el declive de estos dos países, y la participación relativamente equilibrada ( $8 \%$ c/u promedio) de países emergentes como Corea, Taiwán, Malasia, China y México. Sin embargo, para el año 2012 la situación de mercado había cambiado drásticamente y la producción y exportación se concentraba en la China (50\%), distribuyéndose la otra mitad del mercado mundial entre los países ya mencionados. (ver participaciones en Gráficas 9, 10 y 11). Ésta es una muestra del gran poder concentrador de China en las industrias de media y alta tecnología en los inicios del presente siglo, cuyas producciones son favorecidas por estrategias que claramente privilegian el uso de elevadas economías de escala en dinámicos clústeres industriales y comerciales. Según los datos de la OMC, este conglomerado industrial constituye uno de los más activos del comercio mundial y en 2012 originó el 9.3\% del intercambio global. 
Gráfica 9 - Exportación Equipo Oficina Proceso y Telecomunicaciones - Año 1990

\section{China}

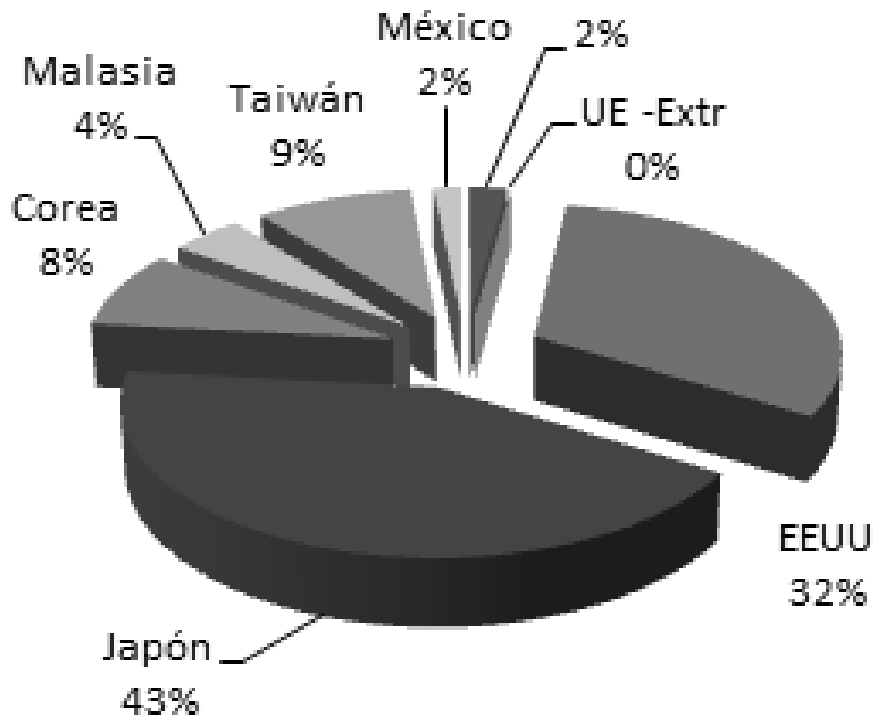

Fuente: World Trade Organization (2013).

Nota: Cálculos del autor con base en cifras de OMC.

Gráfica 10 - Exportación Equipo Oficina Proceso y Telecomunicaciones - Año 2000

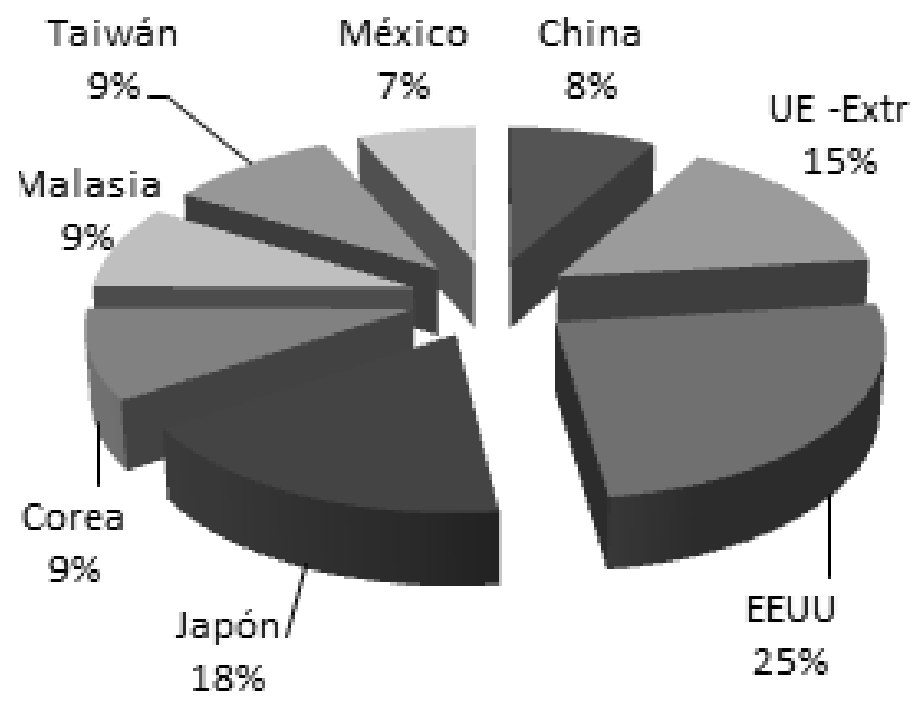

Fuente: World Trade Organization (2013).

Nota: Cálculos del autor con base en cifras de OMC. 

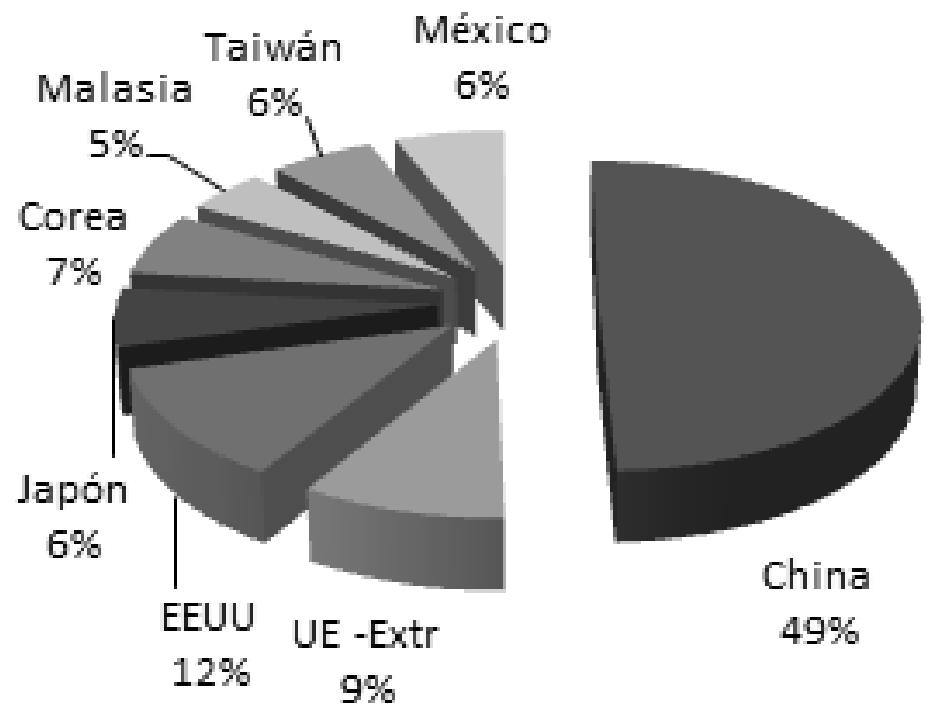

Fuente: World Trade Organization (2013).

Nota: Cálculos del autor con base en cifras de OMC.

\subsection{Rol del Estado Chino en el Sector de Telecomunicaciones}

La estrategia china de apertura al capital y los mercados internacionales iniciada en 1978 tuvo una clara visión del líder reformador Deng Xiaoping. El autor Zicheng lo plantea en los siguientes términos:

El objetivo de modernización que Deng Xiaoping proclamó fue precisamente la transformación de China como país del tercer mundo en uno con poder global, tanto en sentido económico como político. Él planteó: "Nuestros nuevos conceptos son: cuadruplicar el Producto Interno Bruto -PIB y construir una sociedad moderadamente acomodada y moderna, con características chinas." En 1984 Deng propuso una estrategia de desarrollo y modernización de tres pasos. El primero fue doblar el PIB entre 1980 y 1990 . El segundo fue doblarlo otra vez para el año 2000, alcanzando un moderado grado de riqueza. El tercer paso fue alcanzar el nivel medio de los países desarrollados y, básicamente, lograr la modernización hacia el año 2050. (ZICHENG, 2011, p. 74).

Con el ingreso de China a la Organización Mundial del Comercio (OMC) en 2001, su grado de inserción a la economía mundial recibió un gran impulso. Es de tener en cuenta que la apertura implicó la gradual liberalización de diferentes actividades económicas y mayor competencia inter-empresarial -típicas de un sistema capitalista-, pero también que el estado chino mantuvo su política de 
dirección centralizada de la política económica -herencia de planeación socialista y de las antiguas dinastías-, especialmente en ciertas áreas económicas definidas como "sectores estratégicos". ${ }^{5}$ El estado chino ha actuado a través de unas matrices construidas en su primera época socialista, es decir, de la constante transformación de sus grandes empresas estatales, quienes crean condiciones apropiadas para el rápido desarrollo de nuevos procesos, productos y empresas, brindando estímulos al crecimiento de un fuerte tejido empresarial privado y nacional. En el sector de Telecomunicaciones la gigante estatal "China Telecom", que dominaba la prestación de los servicios locales de telefonía antes de la primera reforma y apertura del sector en 1994, se constituyó en la matriz de la transformación del sector. Éste dejó de ser un monopolio para convertirse en un sector oligopólico estatal, a través de la creación de otras empresas estatales gigantes como los proveedores de telefonía móvil "China Unicom" y "China Mobile", y la empresa "China Tie Tong". De forma simultánea al activo intervencionismo estatal, la gradual apertura china ha propiciado el rápido crecimiento de grandes empresas privadas, muchas con socios extranjeros, que crecientemente se insertan como líderes mundiales... y no sólo en el sector de comunicaciones.

La regulación y planeación estratégica del sector es definida por el reformado -en 1998- "Ministerio de la Industria de Información (MII)". La normatividad sólo permitió la inversión extranjera en este sector desde el año 2005 a través de joint ventures con empresas chinas, asociaciones que para tener acceso al gigantesco mercado interno, exigen la transferencia de tecnologías de punta a las nuevas empresas. Todos los grandes consorcios internacionales del sector como Ericsson, Siemens, Nokia, Alcatel y Samsung, entre otros, han establecido sociedades con empresas locales.

El desarrollo del mercado interno chino es de tal magnitud, que el número de suscriptores de la telefonía móvil ascendió en Feb. 2012 a más de mil millones (1.01 $\mathrm{mmm}$ ), cuando logró crecimientos mensuales de 10 millones de abonados (CHINA MOBILE..., 2012), cifra que equivale a los suscriptores registrados en un país como Colombia durante cinco años (VELOZA, 2013). La potencialidad de este enorme mercado es reconocida por los gobernantes chinos y por la dirigencia empresarial como una gran plataforma que les permite desarrollar una activa política industrial y comercial, que combinan a través de exitosas estrategias:

a) Diversificación de la producción y prestación de servicios a partir de empresas matrices del Estado, especialmente en los sectores considerados estratégicos

$5 \quad$ Las siete áreas estratégicas definidas por el Consejo Estatal del Gabinete chino con base en el $12^{\circ}$. Plan Quinquenal 2011-15 son: Protección ambiental y ahorro de energía, tecnología informática de próxima generación, biotecnología, materiales industriales, equipamiento industrial avanzado y nuevas fuentes de energía (CHINA IMPULSARÁ..., 2012). 
b) Estímulos para el crecimiento del sector privado, a través de varias vías: protección y cesión preferencial del mercado interno; abundante financiación de bajo costo; preferencia en obtención de licencias para uso de recursos productivos Vs. empresas extranjeras; dura competencia local entre empresas chinas y con las subsidiarias extranjeras; y provisión estatal de moderna infraestructura productiva

c) Mano de obra calificada, que aunque actualmente de costo salarial creciente, es aún menor que el de los países desarrollados y recientemente industrializados

d) Desarrollo de nuevas tecnologías, a través de la colaboración con empresas extranjeras líderes estimuladas por la participación en el mercado interno, así como con la creciente inversión en investigación y desarrollo tecnológico al interior de las empresas locales

e) Apoyo a la globalización de las empresas chinas (política de go abroad / "salir al mundo").

Estas políticas estatales de amplio espectro han favorecido también el surgimiento de empresas privadas gigantes en diferentes áreas: en equipos de telefonía y similares encontramos empresas como Huawei Technologies, ${ }^{7}$ Great Wall, Shanghai Bell o Zhongxing Tellecommunications Equipment (ZTE), ${ }^{8}$ corporaciones que ya son líderes mundiales del sector. En la actualidad se puede concluir que la política de apertura liderada por Deng Xiaoping estuvo fundamentada en una clara visión global ligada a una eficaz metodología para potenciar los recursos nacionales. En Julio 1983 el liderazgo chino tenía plena conciencia de su "capacidad de atracción" como gran mercado. Según Deng,

Nosotros debemos abrir nuestro país al resto del mundo. Ahora que los europeos occidentales están ocupados con dificultades económicas, no debemos perder tiempo para buscar su cooperación para acelerar nuestra transformación tecnológica... China ofrece un mercado inmenso, muchos países querrán desarrollar la cooperación y hacer negocios con nosotros. Debemos tomar esta oportunidad. Es un asunto de importancia estratégica. (SEN, 2011, p. 84)

Sin embargo, la estrategia china no se resignó al pasivo rol de ser "un gran mercado comprador", sino que se complementa con la del go abroad, iniciando con las empresas estatales, al lado de las cuales también van las grandes corpo-

$6 \quad$ Ampliación de esta estrategia en Finkelstein (2011).

7 Huawei Technologies Co. Ltd. es una empresa privada fundada en 1987 con sede en Shenzhen. Contaba con 140.000 empleados en 2012 y se ubicó como la mayor productora mundial de equipos y redes de comunicaciones desde dicho año, desplazando a la gigante sueca Ericsson. Sus ventas en 2011 fueron de US\$32.4 mil millones (WIKIPEDIA, 2014).

$8 \quad$ ZTE fue fundada en 1985 y tiene su casa matriz en Zhenzhen. Durante los años 2011 y 12 sus 30.000 profesionales del área de investigación ubicados en 3 continentes produjeron cada año el mayor número de patentes del mundo en comunicaciones (ZTE CORPORATION, 2015). 
raciones privadas. Es decir, se ha tomado ventaja de las políticas internacionales/ occidentales que favorecen el "libre mercado", combinándolas con las políticas estatales de apoyo al crecimiento de los negocios chinos.

\subsection{El 12. Plan Quinquenal 2011 - 2015 y la Industria Qúmica}

Otra de las más dinámicas industrias del mundo es la Industria Química. Ella representa un $10.9 \%$ del comercio global (OMC), el cual está dominado por grandes exportadores europeos, norteamericanos y japoneses. La participación china era pequeña en 1990 pero creció exponencialmente entre 2.000 y 2.012, ubicándose como el tercer mayor exportador mundial, superando a dos grandes competidores como Japón y Suiza (Gráfica 12).

Gráfica 12 - Participación de la Exportación de Productos Químicos (\%)

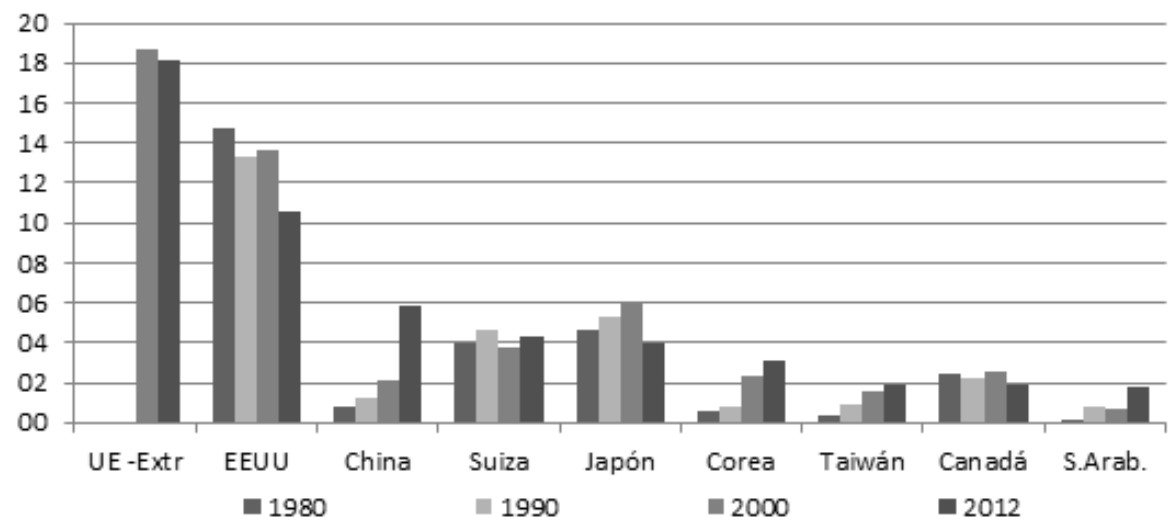

Fuente: World Trade Organization (2013).

Debido a la gran importancia que tiene el petróleo como materia prima en la elaboración de productos químicos y al déficit que presenta China en esta materia (consume más de lo que produce, con tasas de crecimiento que superaron el $20 \%$ anual en períodos recientes), se puede concluir que continuará requiriendo de amplias importaciones. De acuerdo con cálculos del consultor internacional A. T. Kearney, ${ }^{9}$ el consumo de productos químicos de China en 2005 era el $15.4 \%$ del total mundial. Para el 2015 se proyecta que sus importaciones valgan US $\$ 1.37$ billones, con participación del $28.7 \%$ del total (US\$ 4.9 billones), convirtiéndose en el mayor consumidor mundial y por tanto en un jugoso mercado para las corporaciones internacionales del sector. Si tomamos como ejemplo una proyección

9 A. T. Kearney es una empresa consultora internacional fundada en Chicago (EEUU) en 1926. Cuenta con 3.200 analistas ubicados en 40 países del globo y asesora a grandes inversionistas internacionales. 
de la capacidad instalada de producción de plásticos para el 2020 en China (50.6 millones de toneladas) indica que no cubrirá la demanda interna esperada de 74.8 Mill. Ton, es decir, estará una tercera parte por debajo de las necesidades. Factores como éste, sumados a la reestructuración de la visión del desarrollo interno de China, plasmada en el $12^{\circ}$. Plan Quinquenal 2011-2015, implican importantes cambios en las estrategias que promueve el gobierno chino, cambios que conducen a nuevas políticas que inciden en la Industria Química global y en el modelo económico nacional chino.

Una de las reorientaciones del Plan Quinquenal, originada en la desaceleración de las importaciones de los países desarrollados después de la crisis del 2008, indica que la China no puede sustentar su modelo económico centrándose en las exportaciones. Debe por tanto fortalecer su mercado interno y crear las capacidades y estímulos necesarios para realizar dicha tarea. Y para ello se apoya en la política centralizada y utiliza como instrumentos a las empresas estatales, que se constituyen en la punta de lanza para la reorientación de su modelo. Analiza Kearney:

La política del gobierno es complicada para las compañías que trabajan en China, incluso en el mejor de los tiempos [...]. El gobierno de China desempeña numerosas funciones, muchas de las cuales son manejadas por el sector privado en otros países. En China, el gobierno es el organismo normativo y regulador, el prestamista y el banco de inversión, el inversionista, el planificador del uso del suelo y el proveedor de servicios municipales, el definidor de la política industrial, así como también es la organización política que responde a los problemas de salud y empleo. Las decisiones de inversión que el gobierno alienta o demanda suelen ser estratégicas. Por ejemplo, el gobierno ha aumentado su capacidad instalada en la industria de construcción naval en exceso de la demanda proyectada. Sea esto una estrategia preventiva para contrarrestar la competencia o un movimiento agresivo basado en el desarrollo de la industria a largo plazo, habrá un impacto en los competidores internacionales. Esto ya ha sucedido en varias industrias. En el carbón, el cemento y el acero, el control del gobierno de todas las palancas del poder a través de la banca, la inversión de capital, permisos y licencias y la planificación de la infraestructura, está cambiando las cadenas de valor y las estructuras de los clientes. En estas tres industrias, la consolidación aumentará el poder de negociación de los campeones nacionales. En 2015, los 10 principales productores de acero serán propietarios del $60 \%$ de los ingresos de mercado, frente al 43\% en 2009. En el cemento, los 10 mayores serán propietarios del $35 \%$, frente al $23 \%$. El número de pequeños productores de carbón se reducirá de 10.990 a 2.980 entre 2009 y 2015, y su cuota de mercado se reducirá del 68 al 35\%. Hay alrededor de 35.000 empresas químicas en China, la historia y la experiencia sugieren que la consolidación ocurrirá eventualmente. Pero la mano del gobierno es probable que empuje la industria más rápido de lo normal hacia la consolidación. (KEARNEY, 2012, traducción nuestra). 


\section{La Politica Industrial China y la Competencia Internacional}

Con la aceptación por parte de muchos gobiernos nacionales de las recomendaciones del Consenso de Washington acerca del papel marginal que debía jugar en el desarrollo económico la "política industrial", ésta casi desapareció de las agendas de los Estados, especialmente en América Latina. El caso contrario ocurrió en la China. El Banco Mundial reconoce que:

Los logros económicos de la República Popular China durante sus últimos 30 años son remarcables. Se trata de un exitoso y singular caso de desarrollo que aporta valiosas lecciones para otros países que buscan emular dichos éxitos -lecciones acerca de la importancia de adaptar la iniciativa local a la competencia interregional, de integración con el mundo, de adaptación de nuevas tecnologías, construcción de infraestructura de clase mundial, e inversión masiva en su población. En los próximos 15 a 20 años, China está bien posicionado para unirse a los países de alto ingreso. (WORLD BANK, 2013).

Y dentro de la estrategia económica que le ha permitido alcanzar dicho éxito, el Banco Mundial (WORLD BANK, 2013) no deja de reconocer que entre las mayores fortalezas de este país se encuentran sus políticas industriales que:

a) Están orientadas a la utilización de grandes escalas de producción, concentrando el desarrollo en grandes empresas.

b) Han logrado controlar la expansión de sectores que tenían excesos de capacidad instalada y unificar sectores considerados muy fragmentados.

c) Las políticas para estimular el desarrollo tecnológico han conseguido real dimensión económica.

d) El intervencionismo estatal directo ha logrado transferir recursos hacia los sectores priorizados y la adecuada colaboración entre muchos niveles gubernamentales.

\subsection{El Grado de Agregación de Valor en Productos Exportados de China}

La rápida concentración de grandes industrias de moderna tecnología en China permite concluir que este país presenta características bastante favorables para la producción y exportación, que la han convertido en un eje mundial en renglones de media y alta tecnología, lo que ha llevado a muchos analistas a denominarla "la fábrica del mundo". Una pregunta que conviene aclarar se refiere al nivel de "valor agregado chino" en las industrias exportadoras, ya que cada día cobran más importancia las cadenas globales de producción manejadas por empresas transnacionales, que inician el proceso en un país y paso a paso lo van encadenando y sofisticando hasta completarlo como bien final en otra nación del 
globo, donde se le coloca la "Made in ". Adicionalmente, las primeras de estas empresas que se trasladaron a China buscaron beneficiarse del bajo costo inicial de sus salarios.

De acuerdo con las estadísticas del contenido nacional (o valor agregado localmente por incorporación de materiales, trabajo, tecnología y servicios nacionales) de las exportaciones de 25 países, ${ }^{10}$ calculado por la OMC para el año 2008 (Gráfica 13), la China presentó el segundo mayor valor local integrado en las exportaciones de manufacturas, arrojando un 39\% y siendo sólo aventajado por el Japón (45.4\%). Otras economías que superaron el 36\% en la agregación de valor local fueron en su orden EEUU, Tailandia y Alemania. Estos valores corresponden a "promedios", es decir, algunas industrias de cada país superan el promedio mientras otras están por debajo. Aquellos países con menor valor agregado en sus exportaciones manufactureras fueron en su orden: Hong Kong (4.7\%), pues se dedica a la reexportación y su mayor aporte está constituido por Servicios; "Otras" economías (15.2\% de valor agregado); Chile (15.3\%) y Vietnam (16.3\%). Cabe agregar que el promedio global de valor agregado en la exportación de productos industriales en 2008 ("Mundo" 29.5\%), estuvo un 32\% por debajo de la China.

Gráfica 13 - Valor Agregado Nacional en Manufacturas Exportadas - Año 2008 (\%)

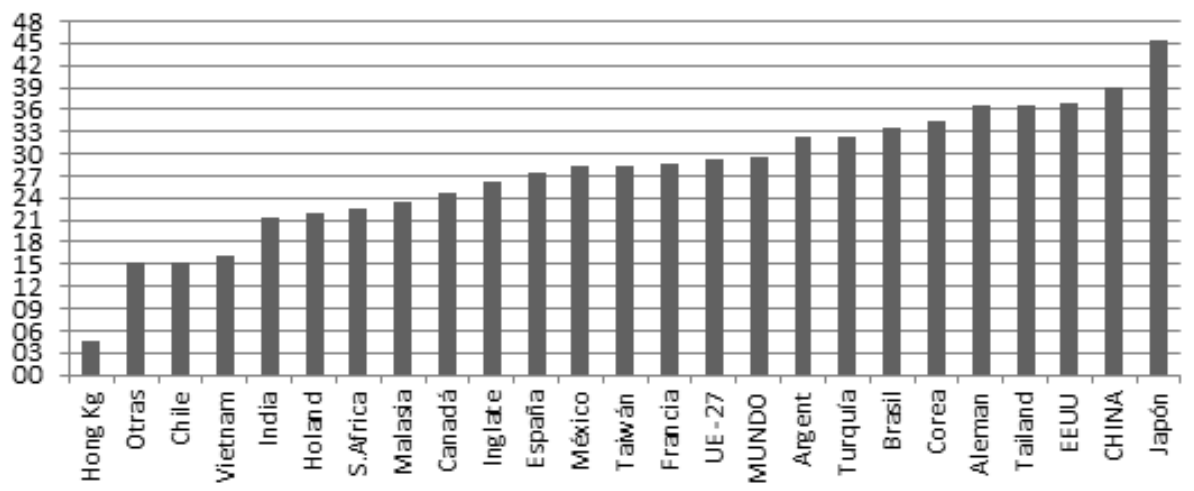

Fuente: World Trade Organization (2013).

10 Entre ellas se incluye un promedio del valor agregado mundial (MUNDO) y un valor para "Otras" economías, que corresponde al promedio del resto de países que no fueron considerados individualmente en el cuadro de la OMC, definidos como países de medio y bajo desarrollo económico. 
Gráfica 14 - Valor Agregado Nacional en Bienes Primarios Exportados - Año 2008 (\%)

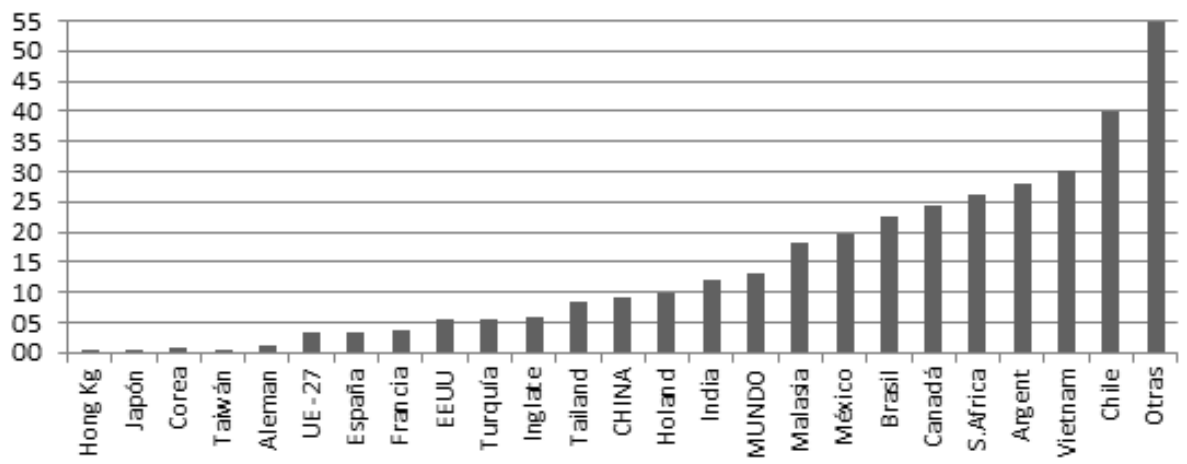

Fuente: World Trade Organization (2013).

Gráfica 15 - Valor Agregado Nacional en Servicios Exportados - Año 2008 (\%)

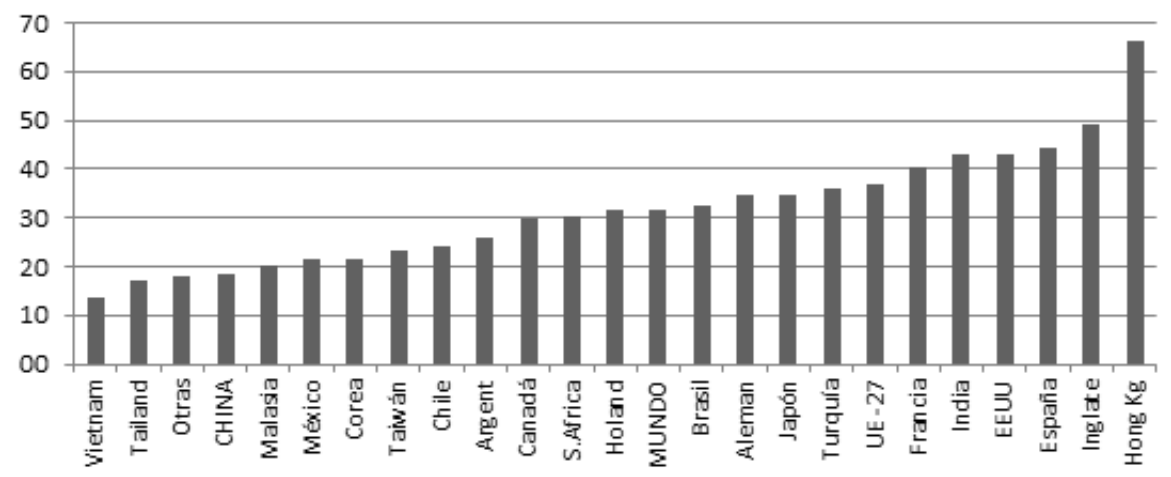

Fuente: World Trade Organization (2013).

Por el contrario, para la Exportaciones de Bienes Primarios (Gráfica 14), la OMC calcula que los países que exhiben menor sofisticación productiva en sus exportaciones son aquellos que se especializan en bienes primarios agropecuarios y mineros. De acuerdo con los 25 países seleccionados, "Otras Economías" presenta la mayor concentración en sus exportaciones primarias, que agregan un $54.6 \%$ de valor local en promedio, mientras que tienden a exportar pocos bienes industriales. Después de "Otras" y en orden descendente encontramos a Chile (39.8\%), Vietnam (30\%), Argentina (28.1\%) y Suráfrica (26.2\%) para el año 2008. La participación de los bienes primarios en la exportación de los países desarrollados tiende a ser baja, no porque no los exporten, sino porque la agregación de valor en manufactura y servicios les posibilita mayor creación de empleo, tecnología y ganancias. En el caso de la China, es clara su estrategia de importar materias pri- 
mas, muchas de ellas de Suramérica y África, para someterlas a transformación y re-exportación con mayor grado de elaboración.

En relación con la generación de valor agregado en los servicios, la Gráfica 15 muestra cómo éstos se concentran en las naciones desarrolladas, la mayoría de las cuales presenta una tendencia al crecimiento de la participación de los servicios modernos en su Producto Interno Bruto, mientras se reducen relativamente la Industria y el sector agropecuario. En el área de Servicios la China todavía se ubica al lado de las naciones exportadoras de relativamente menores niveles de ingreso, indicando su actual menor desarrollo en las empresas de servicios financieros, turísticos, logísticos y otros. Sin embargo, la ciudad de Hong Kong en China presenta el mayor índice de valor agregado en la prestación de servicios en el mundo, característica que puede hacerse extensiva a otras de sus grandes ciudades costeras, como Shanghai, Shenzhen o Quingdao. Estas divergencias evidencian la existencia de grandes diferencias en el conjunto del tejido económico de este gran país, que permite clasificarlo todavía como una nación en proceso de desarrollo.

\subsection{El Empleo de Grandes Economías de Escala Como Elemento Competitivo}

La estrategia china de industrialización masiva y sistemática -especialmente en las ciudades de su amplio litoral- ha permitido el desarrollo creciente de las economías de escala con modernas tecnologías en un número creciente de industrias. Las reformas realizadas a partir de 1978 con apertura económica y liberalización gradual de la competencia interna han estimulado la lucha empresarial entre las propias firmas chinas, entre ellas y las extranjeras (o en joint-ventures con socios chinos), y esta lucha competitiva las prepara para competir internacionalmente por los mercados globales.

Los autores Zhang y Zhou ${ }^{11}$ han analizado los casos de las industrias de electrodomésticos (fabricación de televisores y de hornos microondas), siguiendo las trayectorias de las empresas chinas que a principios de los años 1990 competían a la zaga de subsidiarias de empresas transnacionales japonesas y occidentales. En la medida que su aprendizaje industrial fue perfeccionándose y conquistaron segmentos importantes, aunque minoritarios, del mercado chino, supieron que podían hacer un desarrollo dinámico de sus ventajas comparativas iniciales: su conocimiento tecnológico suficiente para elaborar productos aceptables al mercado, sus redes de distribución regionales y nacionales, sumadas a estructuras de costos menores que las de los líderes internacionales. La confianza en la posición competitiva inicial de algunas empresas locales las alentó a lanzar "guerras de precios” contra las más importantes competidoras extranjeras, que por esa época

11 Zhang, John es profesor de la Wharton School of Marketing en Philadelfia y Zhou, Dongsheng en la China Europe International Business School -CEIBS en Shanghai. 
dominaban los segmentos de consumo de mayor poder adquisitivo y calidad. Las estrategias de reducción de precios y simultáneo incremento en las escalas de producción de las industrias locales produjeron efectos de rápida ampliación de sus participaciones de mercado, sustituyendo parcialmente a sus principales competidores, en un mercado en constante expansión.

Los autores muestran cómo hacia el año 1995, con un mercado en expansión en la industria de televisores, el líder local Changhong participaba con el 16.7\% y "tras unos pocos meses de guerra de precios, la participación global de Changhong creció al 31.6\%” (ZHANG; ZHOU, 2007). Hacia 1997, tras varios episodios en la guerra de precios, las tres mayores marcas de TV a color en China eran locales: Changhong con el 35\%, Konka con el 15\% y TLC con el 10\% del mercado. Las empresas internacionales líderes hasta 1995, tales como como Sony y Phillips, y las chinas que tenían joint ventures con ellas, pasaron de abastecer el 64\% del mercado al 36\% en 1997. El estudio muestra cómo algunas empresas de tamaño medio que pudieron seguir la estrategia de Changhong, también crecieron, mientras que la mayoría de empresas locales, algunas grandes y numerosas pequeñas, vieron reducir sus participaciones o desaparecieron. El mercado de televisores se concentró entre las supervivientes de las luchas de precios.

En la industria de hornos microondas los autores también presentan la experiencia vivida entre 1994 y 2003, en un mercado en rápida expansión y con activa competencia debido a varios episodios de guerras de precios encabezadas por el fabricante local Galanz. Éste participó con un 10\% del mercado en 1994, y después de iniciar su agresiva estrategia competitiva, ascendió al 34.5\% en 1996, desplazando a la empresa chino - estadounidense Whirlpool - Xianhua, líder hasta entonces. Galanz, utilizando tecnología japonesa, tuvo la habilidad de reducir radicalmente sus precios a través de permanentes incrementos en su escala de producción, conservando sus márgenes de utilidad, acrecentando su dominio del mercado y beneficiando a un mayor número de consumidores. Esta carrera condujo a que de 120 productores de hornos microondas en China en 1996, sólo 3 firmas -con liderazgo de Galanz-dominaran el 90\% del mercado en 2003. Los autores del estudio concluyen:

[En China] una firma puede ganar rápidamente participación de mercado si logra desplazar a competidores de menor eficiencia en el manejo de sus costos [...] Sin duda, una industria con un gran número de firmas, con amplia variedad de tamaños y eficiencias productivas, constituye un terreno fértil para las guerras de precios. En China hay muchas de estas industrias, mientras en el Occidente pocas... La existencia de sectores en expansión, con productos de alta elasticidad - precio, puede abrir las puertas a avalanchas de compradores atraídos por menores precios [...]. Esto también implica que cuando una industria madura y nivela sus costos, las guerras de precios disminuyen y la competencia se concentra en factores diferentes del precio. (ZHANG; ZHOU, 2007 p. 24-25). 
Este tipo de experiencias de gran agresividad competitiva por parte de firmas chinas en expansión se repite en las demás industrias locales, y se traslada también a aquellos mercados internacionales donde las condiciones son propicias para penetrar nuevos segmentos.

\section{Efectos Políticos Globales de la Competencia Comercial China}

Se analiza en tres grandes escenarios: 1) Competencia con países desarrollados, 2) Características internas de la población china, y 3) Competencia con países en desarrollo.

\subsection{Respuestas en Estados Unidos a la Competencia China}

El rápido ascenso del comercio chino en múltiples escenarios globales implica fricciones políticas y comerciales con muchos países, y especialmente con el hegemón Estados Unidos. Diversos círculos del gobierno y el empresariado de ese país reclaman negociaciones y/o presiones a las autoridades chinas, como una forma de reducir los impactos negativos en su país. Un informe al Congreso de los Estados Unidos presenta las tensiones con la financiación china a las exportaciones de la siguiente manera:

Durante la visita del vicepresidente chino, Xi Jinping, a Washington en febrero [2012], China se comprometió a participar en negociaciones para llegar a un eventual acuerdo de limitar el financiamiento del gobierno a las exportaciones... Este es un paso potencialmente positivo para contrarrestar las prácticas de promoción de exportaciones de China, muchas de las cuales son perjudiciales y fuera de sintonía con las normas internacionales [...]. Un reciente informe de la "Information Technology and Innovation Foundation (ITIF)" sostiene que China realiza "la campaña de financiación de créditos de exportación más agresiva en la historia”, y señaló que entre 2006 y 2010, el gobierno chino emitió más de US\$203 mil millones en nueva financiación de créditos a la exportación, varias veces más de lo invertido por los Estados Unidos. De acuerdo con el Informe del Ex - Im Bank del 2010 al Congreso de la Unión sobre "Crédito para exportación y Competencia", se concluye que "de arriba a abajo, el tamaño, el alcance y el enfoque de [las instituciones chinas que financian la exportación] es simplemente incomparable con cualquier cosa realizada dentro de la OCDE (Organización para la Cooperación y el Desarrollo Económico). (TUCKER, 2012, traducción nuestra).

Las prácticas de aplicar desde los estados nacionales decididas políticas de estímulos crediticios, subsidios directos a la producción y exportación, apoyo para la adquisición de tecnología, barreras arancelarias y para-arancelarias para defender sus producciones exportables, tasas de cambio devaluadas, construcción de 
infraestructura de servicios productivos, garantía de compras por parte del Estado, presiones políticas y otros tipos de apoyo, han sido prácticas constantes de todos los países desarrollados a través de la historia, tal como lo expone el economista surcoreano Ha-Joon Chang (CHANG, 2003). Ese tipo de políticas e instrumentos, consideradas en el informe al Congreso estadounidense antes citado como "perjudiciales y fuera de sintonía con las normas internacionales”, fueron usadas por prácticamente todos los países hoy desarrollados: en un principio para acortar distancias económicas con otras naciones y potenciar sus industrias hasta alcanzar umbrales de alta competitividad; posteriormente y de manera menos evidente, para mantenerse en las fronteras tecnológicas y en las mejores condiciones económicas y comerciales.

A principios del siglo XXI, la gran nación en proceso de rápido ascenso es la R. P. China, el país más densamente poblada del planeta, que tiene todo un marco político muy pragmático para introducirse en las esferas de la hegemonía multi-polar mundial (ZICHENG, 2011). El rápido desarrollo económico fue definido por su dirigencia política desde la apertura económica de 1979 (NARAYAN, 2011), habiendo implicado sucesivas y graduales reformas de su entorno productivo e institucional. Pero al tiempo que su fuerte dinámica industrial ocasiona conflictos comerciales con las naciones desarrolladas, también multitud de empresas de estos países se aprovechan de las enormes ventajas que ofrece el exitoso "Hub" industrial chino, trasladándole parte de sus industrias y asociándose con productores chinos, bien sea para exportar al resto del mundo como para participar del creciente mercado interno chino, ${ }^{12}$ beneficiándose de sus bajos costos productivos e infraestructura para mejorar sus márgenes de rentabilidad. Es importante observar que a pesar de las fricciones políticas y comerciales, la política exterior china ha sido prudente para integrarse al sistema global y evitar conflictos políticos, especialmente con los Estados Unidos, sin ceder en sus aspiraciones de ocupar un lugar importante en los escenarios mundiales, tal como lo manifiesta el autor Zicheng:

Por un período relativamente amplio de tiempo por venir, no habrá grandes poderes que compitan con el liderazgo de EEUU. Éste es un prerrequisito para el presente estado de cooperación entre los grandes poderes. China tiene ciertamente diferentes perspectivas que los EEUU en dos aspectos: Primero, el liderazgo de EEUU, el cual China no objeta [...] pero nunca podrá reconocerle el derecho de dirigir el mundo. Segundo,

12 La Inversión Extranjera Directa en el Mundo -IED, según cifras del Banco Mundial muestra que para el período 2009 - 2012, la R.P. China fue el principal receptor con US\$ 908 mil millones, seguida por los EEUU con US\$870 mmm. En tercer lugar se ubicó la "región administrativa especial" china de Hong Kong, cuyas inversiones se dirigen en su mayoría a la China continental, con US $\$ 308 \mathrm{mmm}$. El $4^{\circ}$. país mayor receptor de IED fue Brasil con US $\$ 232 \mathrm{mmm}$. y en $5^{\circ}$. lugar se situó Australia con US\$189 mmm. Los países europeos también fueron grandes receptores, a pesar de que con tendencias oscilantes: Alemania recibió en igual período US\$134 mmm., Francia US\$126 mmm. En América Latina destacaron, además de Brasil, Chile con US\$81 mmm, México con US\$ 79 mmm. y Colombia con US\$ 43 mmm (WORLD BANK, 2014). 
China espera que los grandes poderes establecerán la cooperación como base para un mundo multipolar y diverso [...]. En términos generales, el inicio del período de cooperación entre los grandes poderes coincide con el concepto chino de paz y cooperación como el principal tema contemporáneo [...]. El presente escenario internacional ofrece condiciones extremadamente favorables para que China crezca como un poder global. (ZICHENG, 2011, p. 57-58).

Esta cooperación se ha visto materializada en la participación de China en la Organización Mundial del Comercio a partir del 2001, en las iniciativas al interior del Fondo Monetario Internacional para evitar los grandes desequilibrios a raíz de la crisis financiera del 2008, en la inversión de reservas internacionales de China en Bonos del Tesoro de los EEUU, ${ }^{13}$ así como en la intermediación de conflictos políticos en el Medio Oriente, África y Asia, entre otras importantes acciones que contribuyen al equilibrio mundial. Y a la par con su metódica política internacional, sus industrias continúan conquistando nuevos mercados a través del planeta.

\subsection{Economía Dual, Mercados Laborales Urbanos y Rurales en China}

La capacidad productiva de un país está determinada por su capacidad de movilización de recursos económicos, y especialmente de su recurso humano. El rápido desarrollo que hoy experimenta China, de manera similar a la mayoría de países en desarrollo, no ha logrado aún superar la notable diferencia entre zonas urbanas y rurales, entre su costa y el interior. Esta problemática fue advertida por el profesor Arthur W. Lewis ${ }^{14}$ y dio origen a la teoría de la "economía dual" y al reconocimiento de la existencia de un "excedente de trabajadores" que no encuentran ocupación en la economía moderna, o que trabajan con productividades ínfimas en economías rurales de subsistencia. Dicha teoría plantea que si estos trabajadores pueden integrarse a actividades modernas típicas de los sectores industriales, donde la productividad marginal del trabajador se incrementa, esa migración hará crecer el PIB del país. Si la absorción continúa hasta incorporar el último trabajador de baja productividad, desaparecerá la dualidad en la economía y será un indicador del mayor grado de desarrollo. La dirigencia china es consciente de este problema:

La productividad laboral de China es muy baja, sólo una pequeña fracción de la del Occidente [...] las diferencias entre regiones y entre áreas urbanas y rurales es enorme. Existe un gran espacio para el crecimiento

13 China era el mayor inversor en Bonos de la Reserva Federal de los EEUU con US $\$ 1.32$ billones a nov. 2013. Le seguía el Japón con US\$1.19 billones (KATZ, 2014.)

14 A. Lewis publicó su primer trabajo sobre la economía dual en 1954. Una discusión sobre la situación actual en China se presenta en Wang y Weaver (2013). 
continuado, lo que hace muy probable que China mantenga una elevada tasa de crecimiento en el futuro. (ZICHENG, 2011, p. 43-44).

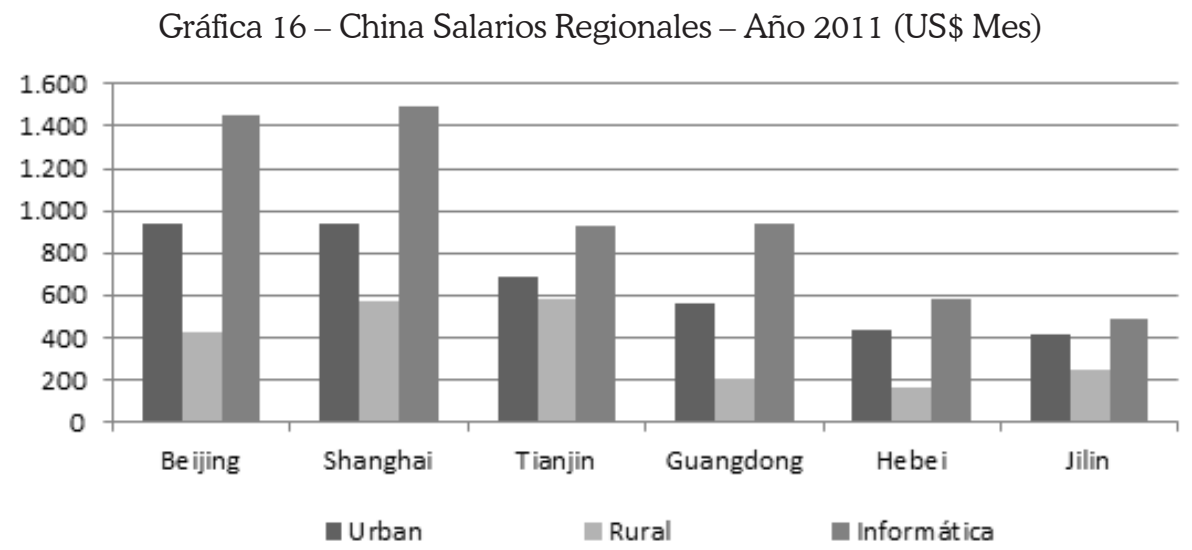

Fuente: China Statistical Yearbook 2012.

Nota: La tasa de cambio de Yuan por US Dólar para 2011 fue de 6.50 Y.

Las diferencias se presentan especialmente entre los mayores centros costeros y las provincias del interior (Gráfica 16). Los salarios urbanos reales crecieron en la China un $12.1 \%$ anual entre los años 2000 y 2011 (CHINA STATISCAL YEARBOOK, 2012), es decir, crecieron 3.5 veces. En 2011 el salario promedio anual fue de 41.799 Yuanes, 2.1 veces mayor que el promedio rural de Y. 19.469. Por su parte, salarios de sectores mejor remunerados como el de Informática en Shanghai o Beijing superaron 7 veces el promedio rural de provincias como Hebei o Jilin. Las diferencias regionales en calidad de vida han propiciado en China la mayor migración y urbanización de la historia humana: 389 millones de personas adicionales se radicaron en sus ciudades en sólo 21 años (Ver Gráfica 11). Entre 1990 y 2011, este país pasó de tener una población urbana de 302 a 691 millones. 


\section{Distribución Población} China 1990

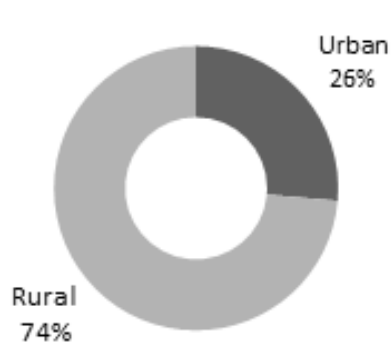

Población R.P. China Año 2000

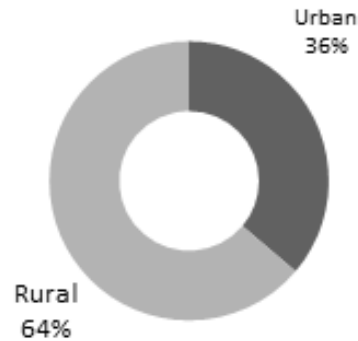

Población China Año 2011

Fuente: China Statistical Yearbook 2012 - Población.

Un gran reto de todos los países en desarrollo consiste en lograr mejorar la calidad de vida de la población migrante, ocupándola también en actividades productivas que superen sus condiciones previas. A manera de comparación se puede observar que la rápida migración que se ha vivido en los países de Latinoamérica no ha logrado dicha asimilación, provocando la formación de enormes cinturones de pobreza y miseria en las grandes ciudades, que se registran en las estadísticas como trabajadores informales, con participación del $47.7 \%$ del total de trabajadores (ORGANIZACIÓN INTERNACIONAL DEL TRABAJO, 2013). Según informe de la Organización Internacional del Trabajo (2013), "La informalidad es persistente en América Latina y el Caribe y está emparentada con la pobreza y la desigualdad. Si no se toman medidas deliberadas pasarán más de 50 años para reducir la informalidad a la mitad." En la China, dadas las políticas adoptadas para mantener un elevado crecimiento económico, una significativa proporción de los migrantes es absorbida por actividades productivas modernas. Por eso su PIB ha crecido cerca del $10 \%$ anual durante tres décadas. Además, la política estatal de continuar apoyando el proceso urbanizatorio ${ }^{15}$ implica que la masiva migración continuará, y que de los 691 millones de chinos que todavía viven en el campo, decenas de millones continuarán desplazándose a las ciudades en el futuro inmediato.

15 El Ministerio de Seguridad Ciudadana informó que al presente viven en las ciudades chinas cerca de 260 millones de trabajadores que no tienen legalizada su estadía en el sistema de registro (Hukou) (BAIJIE, 2013).

La nueva política estatal de urbanización definida en el XVIII Congreso Nacional del PCCh en 2013 contempla: "Para ayudar a los trabajadores migrantes, el sistema de 'hukou' [registro de residencia], el gobierno ha acelerado sus reformas en varias ocasiones en los últimos meses. La más destacable de ellas fue en la tercera sesión plenaria [del Congreso del PCCh], cuando decidió eliminar los controles sobre los campesinos que se establecen en pueblos y ciudades pequeños, así como relajar las restricciones a los asentamientos en ciudades de mediano tamaño. El PCCh se trazó la meta de un nuevo estatus de 'hukou' para 100 millones de obreros inmigrantes a finales de 2020." (NIU, 2014, sin página). 
Si bien China está tomando acciones para conducir sus flujos migratorios, esta nueva y masiva fuerza laboral constituirá una fuerte competencia - vía exportaciones - para los trabajadores de industrias de baja y media tecnología de todas las naciones en desarrollo. De los 405 millones de trabajadores rurales existentes en 2011, una parte importante migrará y encontrará empleo en industrias exportadoras de la costa, mientras que otra se vinculará a los esfuerzos de modernización del interior de China, según las definiciones del XVIII Congreso Nacional del Partido Comunista en 2013, contribuyendo desde ambas áreas a ampliar la capacidad exportadora del país y por tanto, el abastecimiento y competencia con el resto del mundo.

\subsection{La Competencia China con Naciones en Proceso de Desarrollo y la Exportación Mundial de Textiles y Confecciones}

A diferencia de las industrias de alta tecnología que se ubican preferencialmente en países desarrollados y en los recientemente industrializados, las industrias de textiles y confecciones ocupan lugar importante en las exportaciones de la mayoría de naciones en desarrollo. Están entre las mayores generadoras de empleo y constituyen un segmento importante del comercio mundial: US $\$ 286$ mil millones de exportaciones textiles en 2012 y US\$ $423 \mathrm{mmm}$. en confecciones. En las Gráficas 18, 19 y 20 se puede apreciar su cambiante dinámica. En la Gráfica 18 se observa con claridad cómo las exportaciones textiles de China crecieron en forma gigantesca a partir del año 2000 , cuando participaron con el $10 \%$ del total mundial, mientras que en 2012 ascendieron al 33\%. Además de los países desarrollados, otras naciones como Corea, Turquía, India, Pakistán y Taiwán tuvieron participaciones importantes en las exportaciones textiles. Sin embargo, la concentración de la capacidad exportadora en China fue evidente. Con respecto a Latinoamérica, sus exportaciones han sido marginales. Esta región se ha convertido en importadora de textiles. 
Gráfica 18 - Exportación Mundial de Textiles (US\$ Mill.)

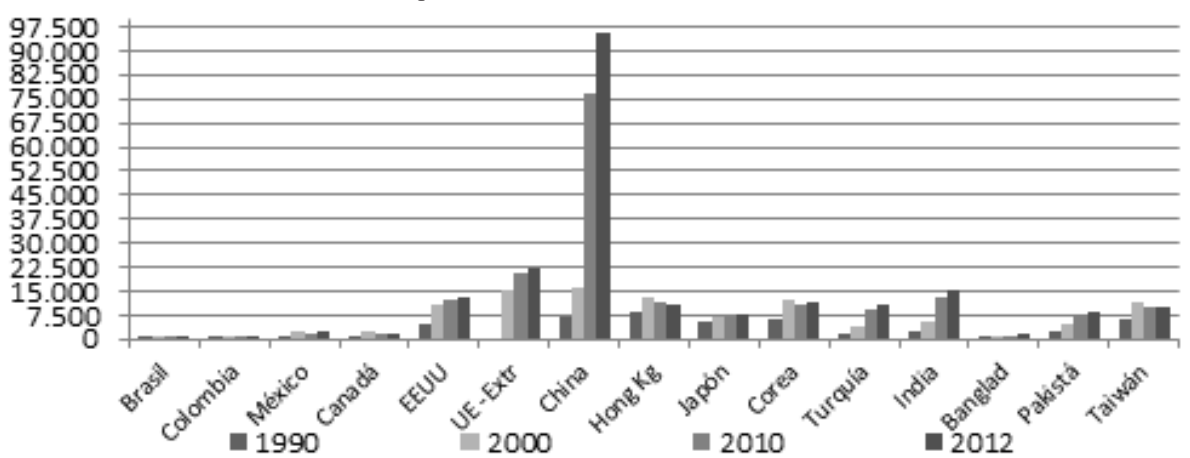

Fuente: World Trade Organization (2013).

Gráfica 19 - Grandes Exportadores de Confecciones (US\$ Mill.)

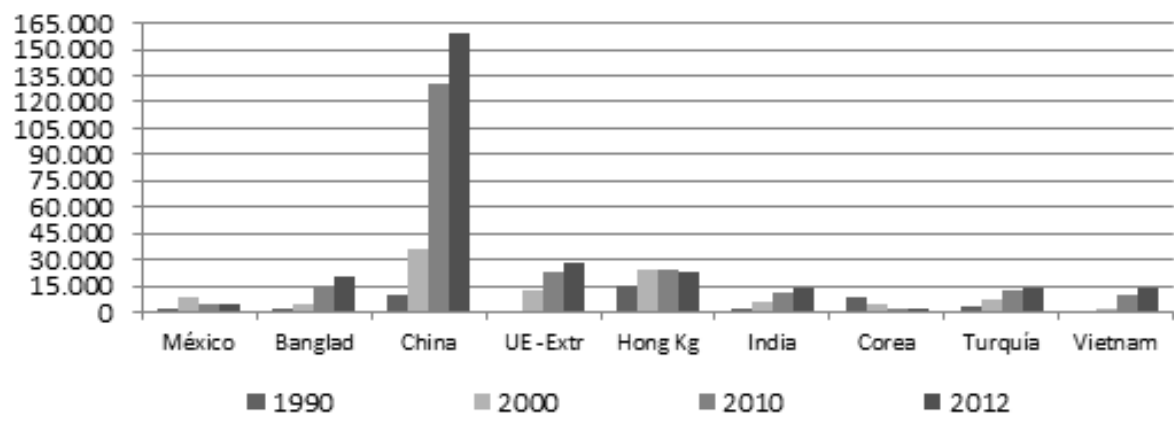

Fuente: World Trade Organization (2013).

Gráfica 20 - Exportación Confecciones A. Latina (US\$ Mill.)

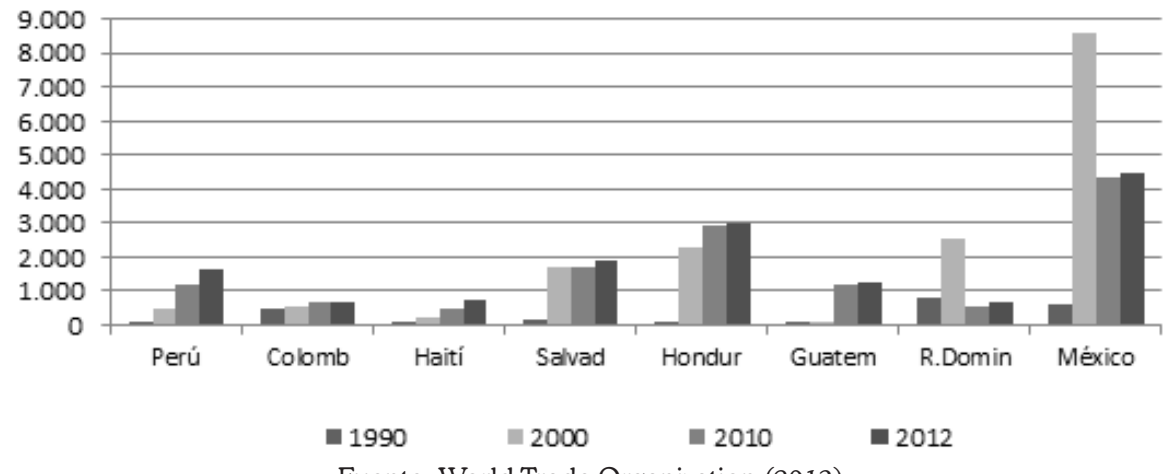

Fuente: World Trade Organization (2013). 
En relación con las exportaciones de Confecciones la historia es similar: En 1990 provenían de China el 9\% de las exportaciones mundiales. En 2012 explicaron el 38\% de ellas (Gráfica 19). De forma más pronunciada que en los textiles, la industria de confección de prendas de vestir es típica de los países en desarrollo tales como Bangladesh, India, Turquía, Filipinas o Vietnam. También en Latinoamérica constituye un importante renglón y especialmente países centroamericanos como El Salvador, Honduras y Guatemala, además de México, generan cientos de miles de empleos y de exportaciones hacia los Estados Unidos. Con respecto a Colombia, Confecciones y Textiles son los sectores que más empleo manufacturero ofrecen (aprox. 650.000 en 2010), y gran parte de él corresponde a empleo femenino e informal (ASOCIACIÓN NACIONAL DE INDUSTRIALES DE COLOMBIA, 2013, sin página). Sin embargo, se aprecia en la Gráfica 20) que la dinámica exportadora colombiana es muy modesta, aun en relación con vecinos como el Perú y los países centroamericanos y caribeños, e inclusive con un país pobre como Haití, que paradójicamente exportó en 2012 un poco más confecciones que Colombia.

Analizando el flujo comercial mundial de textiles y confecciones, y el papel que juega China en él, es evidente que cada año desplaza a nuevos países de sus tradicionales mercados externos: si las ventas mundiales de textiles crecieron entre 1990 y 2012 un $4.7 \%$ anual promedio, las de China lo hicieron al $12.5 \%$. En las confecciones las tasas fueron del 6.4\% y 13.6\% respectivamente (WORLD TRADE ORGANIZATION, 2013), indicando claramente que los productos chinos no sólo abastecen una creciente demanda mundial de textiles y confecciones, sino que también penetran activamente mercados atendidos tradicionalmente por otros productores del mundo en desarrollo. ${ }^{16} \mathrm{El}$ autor Shafaeddin (2002) explica estas afectaciones negativas en términos de pérdidas de participación en el mercado internacional como de orden "competitivo" por la acción del comercio chino, mientras que otros efectos de mercado referidos a las "complementariedades" industriales entre la producción china y las de otras naciones afectan positivamente a aquellas que han mejorado sus capacidades industriales, refiriéndose especialmente a las economías recientemente industrializadas del Asia, quienes ganan participaciones de mercado gracias a sus complementariedades con la producción china y las cadenas internacionales de valor.

Sin demeritar resultados positivos que presenta el abastecimiento con las exportaciones chinas, las implicaciones "competitivas" en los mercados internacionales sobre los niveles de empleo e ingresos por exportación son muy importantes en todos los países en desarrollo, especialmente en aquellos que no logran revo-

16 El enorme esfuerzo industrializante de China implica también un elevado costo por la contaminación ambiental que genera, debido a la matriz energética que utiliza la humanidad actualmente, basada en los hidrocarburos, y a la china que es muy intensiva en el más contaminante de todos: el carbón. El creciente daño ambiental exige cada vez más el desarrollo de nuevas fuentes energéticas, so pena de incrementar el calentamiento global y otros efectos altamente negativos. 
lucionar sus estrategias productivas y competitivas, ni beneficiarse de las "complementariedades” productivas. Y no sólo pierden sus mercados de exportación, sino también los propios mercados internos, donde productos chinos de menores precios desplazan crecientemente las industrias locales de menor competitividad. Este desplazamiento no sólo ocurre en textiles y confecciones, sino también en muchos otros sectores de baja y media tecnología, tales como calzado, productos de madera, de papel, de vidrio, de plástico o del metal. Y dada la gran reserva china de trabajadores aun no calificados, esta competencia se profundizará y tendrá efectos duraderos.

\section{Consideraciones Finales}

En el presente estudio se muestra que la dinámica competencia china está transformando las relaciones comerciales globales a un ritmo sin precedentes en la historia mundial. Al sumar a esto el masivo proceso migratorio interno en China que estimula la continuidad en la producción de bienes intensivos en trabajo, se concluye que este país persistirá ampliando la competencia en ese amplio segmento y desplazando -aun en sus mercados locales- a multitud de productos y trabajadores de los países en desarrollo. La situación no varía sustancialmente con la desaceleración económica ocurrida en China en los últimos meses, pues las políticas exportadoras continúan siendo muy agresivas.

Una gran diferencia entre el desarrollo económico de China y el de otras naciones recientemente industrializadas, como Corea, Taiwán o aun Japón, consiste en que estos países fueron escalando tecnológicamente y se concentraron en productos de mayor complejidad, compitiendo con las naciones desarrolladas, pero al mismo tiempo, abandonaron su elaboración de bienes de baja complejidad. En cambio China ha penetrado la competencia con bienes tecnológicos y no cesa en su producción de bienes de baja complejidad, ya que tiene una enorme reserva de trabajadores migrantes y rurales que seguirán satisfaciendo la producción de bienes exportables que continuarán distribuyéndose por todo el planeta en condiciones competitivas muy favorables.

Desde la apertura al mundo iniciada en 1979, el Estado Chino no sólo continúa proporcionando grandes apoyos al desarrollo de sus industrias y comercio exterior, sino que los complementa con dinámicas de mercado que estimulan la competencia. De esta manera, el Estado sigue auspiciando una robusta política industrial y comercial que garantiza un sólido respaldo a sus empresas para competir en los mercados globales. En buena parte de América Latina por el contrario, las políticas estatales siguen fincadas en el "libre mercado" y la inequitativa distribución de ingresos, mientras el papel reformador del Estado ha sido minimizado. 
Los países en desarrollo que no revolucionen sus tejidos sociales y productivos, no podrán resistir la masiva competencia china. Estructuras productivas conformadas por algunas empresas modernas y muchas con trabajadores de bajas calificaciones técnicas, con maquinarias elementales, con escasos apoyos crediticios y tecnológicos por parte de sus instituciones económicas y estatales, ubicadas en países con infraestructuras deficientes o desarticuladas, difícilmente podrán subsistir. La masiva competencia china sólo se puede afrontar exitosamente con grandes transformaciones de los tejidos sociales y productivos de las naciones en desarrollo.

Un aspecto potencialmente positivo de la competencia china es la exportación masiva a países en desarrollo de máquinas, insumos y herramientas de precios más económicos que los proveídos por otros, las cuales anteriormente difícilmente se podían comprar. La absorción y adaptación de estas tecnologías más accesibles a pequeñas y medianas empresas puede constituir un importante apoyo para abastecer sus mercados locales e insertarse en las cadenas productivas globales, elevando la capacidad competitiva de empresas y trabajadores de las naciones en desarrollo. Sin embargo, se requiere de sólidas, persistentes y dinámicas estrategias para lograr impactos positivos que potencien la capacidad competitiva de los millones de trabajadores del mundo que deben forzosamente competir con el gigante productivo chino en lo que resta del siglo XXI. Buena parte de las naciones del Asia ya lo están haciendo.

\section{Referencias}

ASOCIACIÓN NACIONAL DE INDUSTRIALES DE COLOMBIA. 2013. Disponible en: <www. andi.com.co/downloadfile.aspx?id=8e3f5263-44fe-4df7-9150>. Acceso em: 12 feb. 2014.

BAIJIE, A. Hukou reforms target 2020: official. China Daily. 2013. Disponible en: <http:// www.chinadaily.com.cn/china/2013-12/18/content_17180844.htm > . Acceso en: 15 feb. 2014.

BANCO CENTRAL DE LA REPÚBLICA ARGENTINA. Índice de precios de las materias primas. Buenos Aires: BCRA, Junio 2013. (Gerencia de Análisis Macroeconómico).

CHANG, H. Kicking away the ladder: the "real" history of free trade. Foreign Policy In Focus, Dec. 2003. (FPIF Special Report). Disponible en: <http://www.personal.ceu.hu/corliss/ CDST_Course_Site/Readings_old_2012_files/Ha-Joon\%20Chang\%20-\%20Kicking\%20 Away $\%$ 20the\%20Ladder-The $\% 20 \%$ E2\% $80 \%$ 9CReal\%E2\%80\%9D\%20History\%20of\%20 Free\%20Trade.pdf>. Acceso en: 05 ago. 2014.

CHINA IMPULSARÁ nuevos sectores estratégicos en 2do semestre. Reuters América Latina, 12 jun. 2012. Disponible en: <http://ta.reuters.com/article/topNews/ idLTASIE85B00320120612>. Acceso en: 12 feb. 2014.

CHINA STATISTICAL YEARBOOK 2012: Beijing. 
CHINA MOBILE phone users exceed 1 billion. China Daily, 2012. Disponible en: <http:// www.chinadaily.com.cn/china/2012-03/30/content_14954435.htm>. Acceso en: 11 feb. 14.

COMISSIÓN ECONÓMICA PARA AMÉRICA LATINA Y EL CARIBE. Panorama de la inserción internacional de América Latina y el Caribe: integración regional y cadenas de valor de un escenario externo desafiante. Santiago de Chile, 2014. 143 p.

FINKELSTEIN, D. Commentary on China`s external grand strategy. CNA China Studies, Jan. 2011. Disponible en: <http://www.dtic.mil/dtic/tr/fulltext/u2/a537394.pdf>. Acceso en: 05 ago. 2014.

KATZ, I. China's Treasury Holdings Climb to Record in Government Data. BloombergBussiness. 2014. Disponible en: <http:/www.bloomberg.com/news/2014-01-15/china-s-treasuryholdings-rose-to-record-in-november-data-show.html>. Acceso en: 17 feb. 2014

KEARNEY, A. T. China's chemical industry: flying blind? 2012. Disponible en: < https://www. atkearney.com/documents/10192/647356/Chinas-Chemical-Industry---Flying-Blind.pdf/ d830dd95-dcbf-46a6-afc6-8fcab1fc9204>. Acceso en: 05 ago. 2014.

NIU, S. Trabajadores migrantes se benefician de reforma en el sistema de 'hukou'. Spanish. china.org.cn, 10 jan. 2014. Disponible en: <http://spanish.china.org.cn/txt/2014-01/10/ content_31149525.htm>. Acceso en: 15 feb. 2015.

ORGANIZACIÓN INTERNACIONAL DEL TRABAJO. Economía informal en América Latina y el Caribe. 2013. Disponible en: < http://www.ilo.org/americas/temas/econom\%C3\%ADainformal/lang--es/index.htm>. Acceso en: 30 jul. 2015.

SEN, N. C. China's economic reform: ideological legitimacy and Deng Xiaoping theory. London: Frontpage Publications Limited, 2011.

SHAFAEDDIN, S.M. The Impact on China's accession to WTO on the exports of developing countries. United Nations Conference on Trade and Development, 2002. (UNCTAD discussion papers, n. 160).

TUCKER, A. Export assistance and the China challenge. Washington, D.C.: U.S.-China Economic and Security Review Commission, Apr. 2012. (Staff Research Backgrounder, n. 1).

VELOZA, C. Ministerio de las TIC da a conocer las cifras de abonados a la telefonía celular en Colombia. Siglo Data MMI Blog, 25 jul. 2013. Disponible en: < http://colombia.mmi-e. $\mathrm{com} / \mathrm{blog} /$ category/sector/tic/ministerio-de-las-tic-da-conocer-las-cifras-de-abonados-loscelulares-en-co > . Acceso en: 12 feb. 2014.

WANG, X.; WEAVER, N. Surplus labor and lewis turning points in China. Journal of Chinese Economic and Business Studies, v. 11, n. 1, p. 1-12, 2013.

WIKIPEDIA. Huawei Technologies Co. Ltd. Disponible en: < http://es.wikipedia.org/wiki/ Huawei>. Acceso en: 12 feb. 2014.

WORLD BANK. China 2030: building a modern, harmonious, and creative society. Washington, D.C.: The World Bank and the Development Research Center of the State Council, 2013. 
WORLD BANK. Foreign direct investment, net inflows (BoP current US\$). Disponible en: < http://data.worldbank.org/indicator/BX.KLT.DINV.CD.WD>. Acceso en: 17 feb. 2014.

WORLD TRADE ORGANIZATION. International Trade Statistics 2013: Merchandise Trade. 2013. Disponible en: < http://www.wto.org/english/res_e/statis_e/its2013_e/its13_merch_ trade_product_e.htm>. Acceso en: 09 ene. 2014.

ZHANG, J.; ZHOU, D. The art of price war: a perspective from China. Shanghai: CEIBS, 2007.

ZICHENG, Y. Inside China's grand strategy: the perspective from the people's republic. Lexington, Kentucky: The University Press of Kentucky, 2011.

ZTE CORPORATION. About ZTE. 2015. Disponible en: < http://wwwen.zte.com.cn/en/ about/corporate_information>. Acceso en: 12 feb. 2014.

Recebido em: 12/11/2014. Aceito em: 12/02/2015. 